\title{
DECONTAMINATION BY CLEANING WITH FLUOROCARBON SURFACTANT SOLUTIONS
}

R. Kaiser ${ }^{1}$

C. E. Benson

E. S. Meyers

V. C. A. Vaughen ${ }^{2}$

\begin{abstract}
'Entropic Systems, Inc., P.O. Box 397, Winchester MA 01890-0597.
${ }^{2}$ Chemical Engineering and Safety Consulting Services (Vaughen Enterprises), 1136 Harrogate Dr., Knoxville TN 37923-1953.
\end{abstract}

Date Published: February 1994

\author{
Prepared by \\ OAK RIDGE NATIONAL LABORATORY \\ Oak Ridge, Tennessee 37831-6285 \\ managed by \\ MARTIN MARIETTA ENERGY SYSTEMS, INC. \\ for the \\ U.S. DEPARTMENT OF ENERGY \\ under contract DE-AC05-84OR21400
}


CONTENTS

$\underline{\text { Page }}$

LIST OF FIGURES $\ldots \ldots \ldots \ldots \ldots \ldots \ldots \ldots \ldots \ldots \ldots \ldots \ldots \ldots \ldots$

LIST OF TABLES $\ldots \ldots \ldots \ldots \ldots \ldots \ldots \ldots \ldots \ldots \ldots \ldots \ldots \ldots \ldots \ldots$

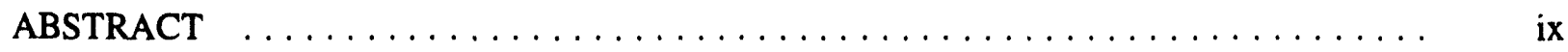

1. INTRODUCTION $\ldots \ldots \ldots \ldots \ldots \ldots \ldots \ldots \ldots \ldots \ldots \ldots \ldots \ldots \ldots \ldots$

2. PROCEDURES $\ldots \ldots \ldots \ldots \ldots \ldots \ldots \ldots \ldots \ldots \ldots \ldots \ldots \ldots \ldots \ldots \ldots$

2.1 DESCRIPTION OF THE TEST SEQUENCES $\ldots \ldots \ldots \ldots \ldots \ldots \ldots \ldots$

2.2 PROCEDURE FOR THE CLEANING PROCESS $\ldots \ldots \ldots \ldots \ldots \ldots \ldots$

2.3 PROCEDURE FOR PREPARING RINSE AND

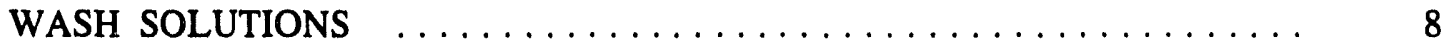

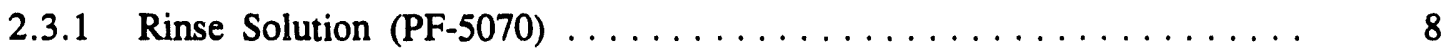

2.3.2 Wash Solution $[\mathrm{PF}-5070-1$ wt \% K157FS(M)
or K157FS(L)] $\ldots \ldots \ldots \ldots \ldots \ldots \ldots \ldots \ldots \ldots \ldots \ldots \ldots$

2.4 PREPARATION OF CONTAMINATED TEST PIECES $\ldots \ldots \ldots \ldots \ldots \ldots$.

2.4.1 Washer Test Assemblies (WTAs) $\ldots \ldots \ldots \ldots \ldots \ldots \ldots \ldots \ldots \ldots$

2.4.2 Mechanical Components ................... 9

2.4.3 Contamination of Test Assemblies
and Manipulator Parts $\ldots \ldots \ldots \ldots \ldots \ldots \ldots \ldots \ldots \ldots$

2.5 PROCEDURE FOR DETERMINING THE LEVEL OF

ULTRASONIC AGITATION $\ldots \ldots \ldots \ldots \ldots \ldots \ldots \ldots \ldots \ldots \ldots \ldots . \ldots \ldots$

2.6 FILTRATION TESTS AND FLUID RECOVERY $\ldots \ldots \ldots \ldots \ldots \ldots \ldots \ldots$

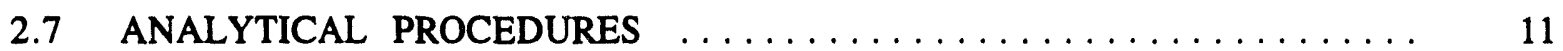

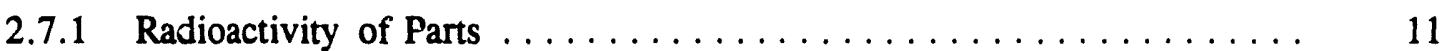

2.7.2 Surfactant Concentration $\ldots \ldots \ldots \ldots \ldots \ldots \ldots \ldots \ldots \ldots \ldots \ldots \ldots$

2.7.3 Used or Recycled Diluent or Rinse Solution . . . . . . . . . . . . . . 12

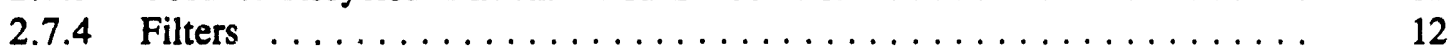

3. EXPERIMENTAL EQUIPMENT $\ldots \ldots \ldots \ldots \ldots \ldots \ldots \ldots \ldots \ldots \ldots \ldots$

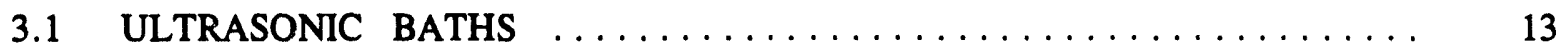

3.2 FILTRATION EQUIPMENT $\ldots \ldots \ldots \ldots \ldots \ldots \ldots \ldots \ldots \ldots \ldots \ldots \ldots \ldots$ 
3.3 ANALYTICAL MEASURING EQUIPMENT $\ldots \ldots \ldots \ldots \ldots \ldots \ldots \ldots$

3.4 OTHER EQUIPMENT $\ldots \ldots \ldots \ldots \ldots \ldots \ldots \ldots \ldots \ldots \ldots \ldots \ldots \ldots \ldots \ldots \ldots$

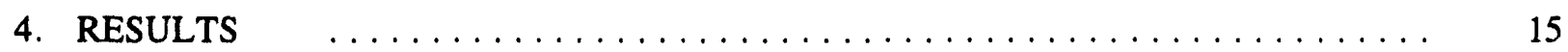

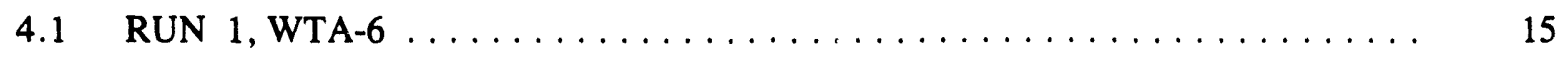

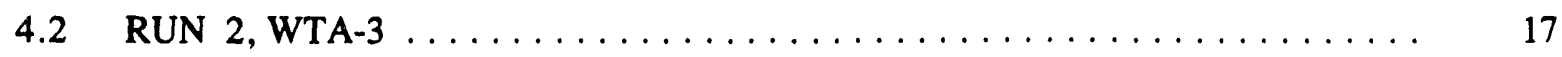

4.3 RUN 3, MANIPULATOR WRIST HOUSING (WL) $\ldots \ldots \ldots \ldots \ldots \ldots$

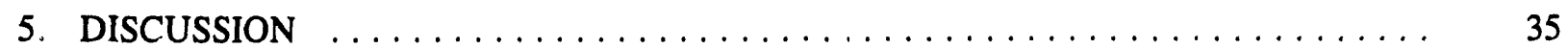

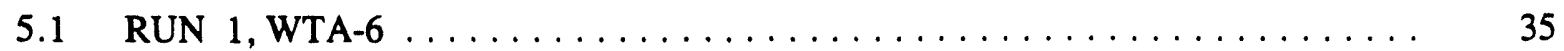

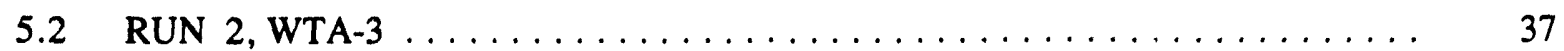

5.3 SUMMARY OF THE WTA RESULTS $\ldots \ldots \ldots \ldots \ldots \ldots \ldots \ldots$

5.4 RUN 3, MANIPULATOR WRIST HOUSING (WL) $\ldots \ldots \ldots \ldots \ldots \ldots$

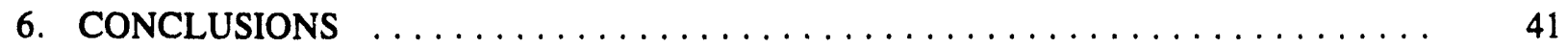

7. RECOMMENDATIONS FOR FUTURE WORK $\ldots \ldots \ldots \ldots \ldots \ldots \ldots \ldots \ldots$

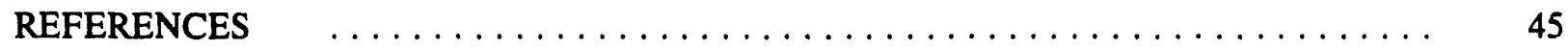

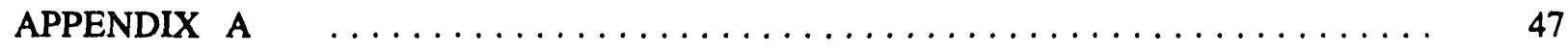




\section{LIST OF FIGURES}

Figure

$\underline{\text { Page }}$

1 Decontaminating WTA-6 (pancake probe readings) $\ldots \ldots \ldots \ldots \ldots \ldots \ldots \ldots$

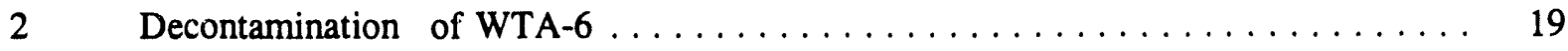

3 Decontaminating WTAs 3 and 6 (pancake probe readings) $\ldots \ldots \ldots \ldots \ldots \ldots$

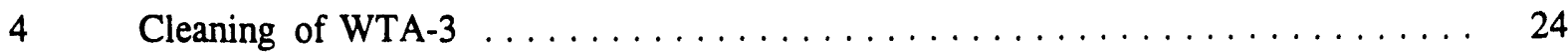

5 Decontaminating a manipulator wrist housing (WL)

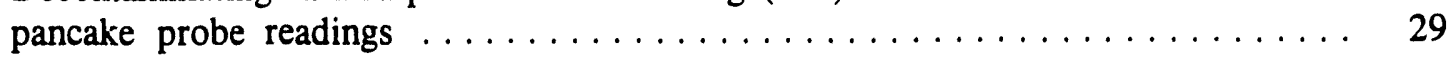

6 Decontamination of a manipulator wrist housing $\ldots \ldots \ldots \ldots \ldots \ldots \ldots$

A.1 Absorbance of wash solution for $\operatorname{Krytox}(\mathrm{M})$ in $\mathrm{PF} 5070 \ldots \ldots \ldots \ldots \ldots$

A.2 Absorbance of wash solution for $\operatorname{Krytox}(L)$ in PF $5070 \ldots \ldots \ldots \ldots \ldots \ldots$

A.3 Standard curve for Krytox $157 \mathrm{FS}(\mathrm{M})$ in PF $5070 \ldots \ldots \ldots \ldots \ldots \ldots$ 


\section{LIST OF TABLES}

$\underline{\text { Table }}$

Page

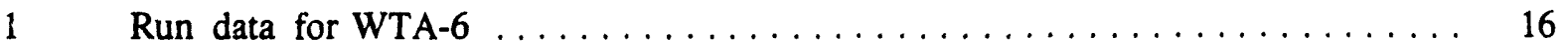

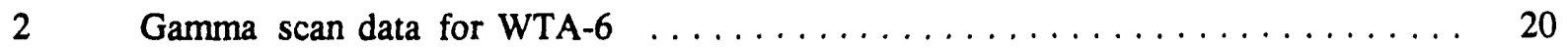

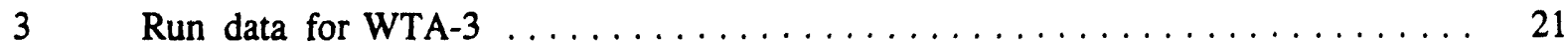

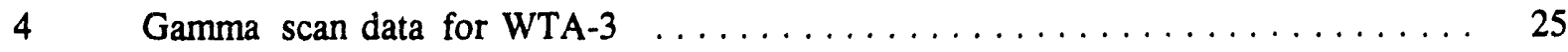

$5 \quad$ Run data for manipulator wrist housing (WL) $\ldots \ldots \ldots \ldots \ldots \ldots \ldots \ldots \ldots$

6 Gamma scan data manipulator wrist housing (WL) $\ldots \ldots \ldots \ldots \ldots \ldots \ldots \ldots$

$7 \quad$ Smear data for the disassembled manipulator housing

(WL), Run 3 (in disintegrations per minute per $100 \mathrm{~cm}^{2}$ ) $\ldots \ldots \ldots 33$

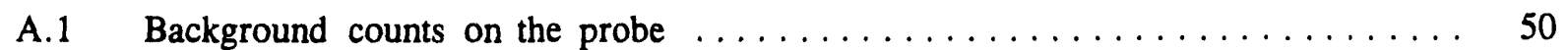

A.2 Probe data and averages: ESI Runs 1 through $3 \ldots \ldots \ldots \ldots \ldots \ldots \ldots$

A.3 Comparison of probe readings for sample WTA-6

through a plastic bag and through a petrie dish 


\section{ABSTRACT}

In the nuclear industry, facilities and their components inevitably become contaminated with radioactive materials. This report documents the application of a novel particle-removal process developed by Entropic Systems, Inc. (ESI), to decontaminate critical instruments and parts that are contaminated with small radioactive particles that adhere to equipment surfaces. The tests were performed as a cooperative effort between ESI and the Chemical Technology Division of the Oak Ridge National Laboratory (ORNL).

ESI developed a new, environmentally compatible process to remove small particles from solid surfaces that is more effective than spraying or sonicating with CFC-113. This process uses inert perfluorinated liquids as working media; the liquids have zero ozone-depleting potential, are nontoxic and nonflammable, and are generally recognized as nonhazardous materials.

In the ESI process, parts to be cleaned are first sprayed or sonicated with a dilute solution of a high-molecular-weight fluorocarbon surfactant in an inert perfluorinated liquid to effect particle removal. The parts are then rinsed with the perfluorinated liquid to remove the fluorocarbon surfactant applied in the first step, and the residual rinse liquid is then evaporated from the parts into an air or nitrogen stream from which it is recovered.

Nuclear contamination is inherently a surface phenomenon. The presence of radioactive particles is responsible for all "smearable" contamination and, if the radioactive particles are small enough, for some of the fixed contamination. Because radioactivity does not influence the physical chemistry of particle adhesion, the ESI process should be just as effective in removing radioactive particles as it is in removing nonradioactive particles. 
The concept here was to use the ESI process to remove radioactive particles from large contaminated objects. The suspended radioactive particles were then removed from the process liquid by filtration to allow liquid recycle and disposal of the filter and particles as waste. The perceived advantage is that this process greatly reduces the volume of radioactive waste requiring disposal and allows valuable equipment to be salvaged.

The main goals of the experiments performed at ORNL were to (1) demonstrate that the ESI process removes a variety of radioactive particulates from complex parts; (2) demonstrate that these complex mechanical parts can be decontaminated to "green tag" tolerances by this process; (3) compare the rate and completeness of decontamination using a perfluorinated liquid with no additives with that of a perfluorinated liquid containing a perfluorinated surfactant; and (4) demonstrate that any radioactive materials present in the used perfluorinated liquid could be removed by simple physical means, such as filtration or decantation, to allow solvent recycle.

This report discusses the fluorocarbon surfactant solutions and presents a summary of radiological and other data compiled during the demonstrations. 


\section{INTRODUCTION}

This report documents the application of a novel particle-removal process that was developed by Entropic Systems, Inc. (ESI), to decontaminate critical instruments and parts of small radioactive particles that adhere to the surfaces of equipment. The tests were performed in a cooperative effort between ESI and the Chemical Technology Division (CTD) of the Oak Ridge National Laboratory (ORNL).

In the nuclear industry, facilities and their components inevitably become contaminated with radioactive materials. While contamination may result from chemical reactions between radioactive process materials and the materials used in the construction of these facilities and components, contamination is most often caused by the deposition of thin films of fine adherent radioactive particles, especially in the case of accidental discharge, that are not chemically bonded to the substrates.

Design and operational procedures contribute to minimize these effects, but decontamination is a necessary process in reducing radiation levels in the working environment. Whereas facilities are occasionally cleaned either for reuse or decommissioning, components from active areas commonly require decontamination for reuse or maintenance operations on a much more frequent schedule.

Decontamination has been defined as "the removal of unwanted radionuclides from surfaces" (Ayres, 1970). Decontamination processes are similar to traditional surface-cleaning processes that remove unwanted nonradioactive surface contaminants -except for the types of contaminants and, to a certain extent, the degree of removal. Nuclear decontamination requires an essentially complete level of contaminant removal $-\mathrm{a}$ high level of cleaning that is required by only select manufacturing operations that are very sensitive to foreign contaminants, such as the semiconductor industry. As a result, most of the decontamination processes now used in the 
nuclear industry involve abrasive mechanical operations or aggressive cleaning solutions (Ayres, 1970; Rankin and McGlynn, 1989). The mechanical methods are destructive because to attain the required degree of decontamination, the external surface layer of the object being decontaminated is removed along with the contaminating radionuclides. Most cleaning solutions are water based and may contain detergents, sequestering agents, acids or bases, inhibitors, etc. These solutions are usually applied under conditions of high shear with apparatuses that range from agitated tanks to high-pressure jets.

With the exception of chlorinated solvents such as trichloroethylene (TRIC) and chlorofluorocarbons (CFCs) such as trichlorotrifluoroethane (CFC-113), organic liquids have been used to a very limited extent as cleaning media in the nuclear industry because of safety concerns, particularly flammability. CFC-113 base liquids have been of particular interest to the nuclear industry because they can be used to clean electrical components without damage and to clean product-contaminated material without the risk of criticality (Bond and Keasey, 1984). Highpressure spraying of CFC-113 has been found to be a particularly effective means of removing radioactive particulate contamination from devices, including electrical equipment and hardware (Ashley, 1984).

Decontamination processes based on CFCs are now obsolete. Because of new evidence that the earth's atmospheric ozone shield may be weakening faster than previously thought, President Bush announced in early 1992 that under the provisions of the Clean Air Act of 1990, the production of all chemicals known to be sources of atmospheric chlorine, including CFC-113 and TRIC, will be banned after December 31,1995 . As a consequence, after that date no viable method of reclaiming radioactively contaminated electronic and other sensitive, high-value equipment will be available to the nuclear industry. 
ESI has developed a new, environmentally compatible process to remove small particles from solid surfaces that is more effective than spraying or sonicating with CFC-113. The process uses inert perfluorinated liquids as working media; the liquids have zero ozone-depletion potential, are nontoxic and nonflammable, and are generally recognized as nonhazardous materials. These liquids are compatible with delicate electronic and electromechanical equipment.

In the ESI process, the parts to be cleaned are first sprayed or sonicated with a dilute solution of a high-molecular-weight fluorocarbon surfactant in an inert perfluorinated liquid to effect particle removal. The parts are then rinsed with the perfluorinated liquid to remove the fluorocarbon surfactant applied in the first step, and the residual rinse liquid is then evaporated from the parts into an air or a nitrogen stream from which it is subsequently recovered.

Phasex Corporation of Lawrence, Massachusetts, and ESI recently completed Phase I of an Air Force-sponsored Small Business Innovative Research program (AF 91-186) to develop new processes to replace existing CFC-113 for cleaning operations of precision parts. The approach taken was to remove oils by supercritical fluid (Phasex) and to remove particles with fluorocarbon surfactant solutions (Gallagher, Krukonis, and Kaiser, 1992). Phasex and ESI were awarded a Phase-II program, which started in June 1992.

One order of magnitude increase in the rate and extent of particle removal was observed when inertial guidance instrument parts were ultrasonically cleaned in a dilute solution of a Krytox ${ }^{\mathrm{TM}}$ surfactant, a carboxylic acid-terminated oligomer of hexafluoropropyleneoxide (HFPO carboxylic acid), in a perfluorinated liquid instead of CFC-113. It has also been demonstrated that adsorbed HFPO carboxylic acid can be removed from metal washers and from instrument parts by simple extraction with a surfactant-free fluorinated liquid.

Nuclear contamination is inherently a surface phenomenon. Much nuclear waste is the result of the deposition of radioactive particles onto nonradioactive substrates. The presence of 
radioactive particles is responsible for all "smearable" contamination and, if the radioactive particles are small enough, for some of the fixed contamination. Because radioactivity does not influence the physical chemistry of particle adhesion, the ESI process should be just as effective in removing radioactive particles as it is in removing nonradioactive particles.

The concept is to use the ESI process to remove radioactive particles from large and, therefore, costly-to-dispose-of contaminated objects of high inherent value. The suspended radioactive particles are then removed from the process liquid by filtration so that the liquid can be reused. The radioactive particles from the decontaminated parts accumulate on the filter. The filter and the captured particles are periodically disposed of as radioactive waste. The perceived advantage of the proposed process is that it greatly reduces the volume of the radioactive waste requiring disposal and allows valuable equipment to be salvaged.

The feasibility of using the ESI process for nuclear decontamination was demonstrated in a recently completed U.S. Nuclear Regulatory Commission study (Kaiser and Harling, 1993). The major results of this study are as follows:

1. The fluorocarbon surfactant solutions used as working media in the ESI process survived exposure of up to 10-Mrad doses of gamma rays with only minor changes; thus they are considered sufficiently radiation resistant.

2. Ultrasonic cleaning in perfluorinated surfactant solutions was found to be an effective method of removing radioactive iron $\left({ }^{59} \mathrm{Fe}\right)$ oxide particles from test pieces contaminated by immersion in a suspension of radioactive iron oxide powders in a carrier liquid.

3. The suspended radioactive particles could be ql'antitatively removed from the process liquids by filtration through a $0.1-\mu \mathrm{m}$ memb ane filter.

The major limitation of the previous study was that it examined only the removal of radioactive iron oxide from parts artificially contaminated by immersion in a suspension of this powder. 
ORNL is a multipurpose research and development (R\&D) facility operated by Martin Marietta Energy Systems, Inc., for the U.S. Department of Energy. Since its establishment in the early 1940s, ORNL has operated numerous facilities that have generated radioactively contaminated materials as a by-product of other activities. The contamination originates in facilities such as research reactors, radiochemical pilot plants, radioisotope production facilities, and numerous R\&D laboratories. A major mission of Energy Systems during the 1990s is environmental cleanup and compliance to health and safety requirements. In pursuit of this mission, numerous remediation projects are under way, and many others are being planned. These projects present an opportunity for ORNL to restore its facilities to a much cleaner condition and to use its expertise in addressing other national environmental problems. In response to the growing need for efficient decontamination techniques and equipment to conduct remediation projects, the Radiochemical Tecinology Section of CTD formed a group whose primary mission is decontamination technology development (DTD). The objective of the group is to design new equipment, to identify new applications of existing technology for decontamination activities, and to evaluate equipment capabilities through decontamination demonstrations.

To furtht: these objectives, DTD coordinated a cooperative endeavor between ESI of Winchester, Massachusetis, and CTD to test whether ESI's patented process for removing common particulates from surfaces was effective also for removing radioactive particulates. ESI directed the tests at ORNL. Personnel in CTD provided laboratory space, contaminated samples, analytical services, and technical support personnel for performing the tests.

The research addressed the application of ESI's particle-removal process to the nondestructive decontamination of nuclear equipment. The cleaning medium used in this process is a solution of a high-molecular-weight fluorocarbon surfactant which in an inert perfluorinated 
liquid results in enhanced particle removal. The perfluorinated liquids of interest, which are recycled in the process, are nontoxic, nonflammable, and environmentally compatible because they do not present a hazard to the ozone layer.

The main goals of the experiments performed at ORNL were as follows:

1. To demonstrate that the ESI process can remove a variety of radioactive particulate contaminants from complex parts, not just radioactive iron oxide powders.

2. To demonstrate that complex mechanical parts that are contaminated only with radioactive particles can be decontaminated to "green-tag" tolerances by this process. For parts that have a combination of radioactive particulates and chemically bonded (fixed) radioactivity, the purpose is to demonstrate that the items can be cleaned to meet "greentag" tolerances, that is, to remove the particulate matter.

3. To compare the rate and completeness of decontamination using a perfluorinated liquid with no additives with that of a perfluorinated liquid containing a perfluorinated surfactant.

4. To demonstrate that any radioactive materials present in the used perfluorinated liquids were removed by simple physical means, such as decantation, filtration, or distillation, so that the solvents may be recycled.

This report discusses the fluorocarbon surfactant solutions and presents a summary of radiological and other data compiled during the demonstrations. 


\section{PROCEDURES}

\subsection{DESCRIPTION OF THE TEST SEQUENCES}

In the first two runs, the part was cleaned in a series of cycles using rinse soiution [pure perfluoroheptane (PF-5070)] followed by a series of cleaning cycles using the wash solution (a 1\% solution of a HFPO carboxylic acid surfactant in PF-5070), followed again by a final rinse to remove any adsorbed surfactant from the part. In Run 3, the initial cleaning was with the wash solution, followed by the rinse; the initial washing and rinsing were then followed by more washes and ended with a manual rinse.

\subsection{PROCEDURE FOR THE CLEANING PROCESS}

Each part was placed in a clean, dry $600-\mathrm{mL}$ stainless steel beaker. Between 150 and $500 \mathrm{~mL}$ of liquid was preheated to about $60^{\circ} \mathrm{C}$ and degassed for at least 5 min under ultrasonic agitation and added so that the liquid surface was at least $2 \mathrm{~cm}$ above the top of the part. The beaker was covered with a petrie dish to prevent bath water from splashing into the beaker. The dry part was allowed to soak in the cleaning liquid for $20 \mathrm{~min}$ the first time it was cleaned before the

ultrasonic power was turned on. (A waiting period of $5 \mathrm{~min}$ between adding the preheated liquid to the part for subsequent cleaning cycles and initiating the ultrasonic agitation was used as a standardized equiiiibration period.)

After sonification, the part was removed from the beaker with a pair of tongs, thus allowing any liquid adhering to the part to drain back into the beaker. 'Then the part was placed in a bottle and was rinsed with a fresh solution of the type used in the previous cleaning cycle using a wash bottle. The wash liquid was collected in a used solvent container. 
The washed part was placed in a clean plastic bag and counted on a portable "pancake" betagamma probe. At selected intervals, the bagged part was analyzed using a NOMAD gamma ray counter. (Details are given in Sect. 2.7.) The solution left in the beaker was sampled after an additional $1 \mathrm{~min}$ of ultrasonic agitation to resuspend any particulate matter and homogenize the solution.

The beaker was then removed from the ultrasonic bath, and the residual liquid was filtered by gravity through either a 0.1 - or a $0.2-\mu \mathrm{m}$ filter membrane. While filtering, the solution was checked for any sign of turbidity or settled layers. (A part that is oily may release the oil to the solution where it will eventually settle out as a separate layer because perfluorinated liquids are notoriously poor solvents for oils or most other liquids. A settled layer may be either on top of or under $^{1}$ the perfluorinated liquid.)

This completed a typical cleaning cycle in a decontamination test run.

The previous process was repeated for further cycles until the radioactivity of the part became constant -as implied by successive beta-gamma probe results showing little change in residual activity.

After all the cleaning cycles were completed, the cleaned part was washed with fresh (surfactant-free) perfluorinated liquid to remove any residual surfactant chemicals. The cleaned part, the liquid samples, and the filters were collected for analysis.

\subsection{PROCEDURE FOR PREPARING RINSE AND WASH SOLUTIONS}

\subsubsection{Rinse Solution (PF-5070)}

Perfluoroheptane (PF-5070 by 3M Corporation) from the shipping container was used as the rinse solvent and as the diluent for the wash solution described below.

\footnotetext{
${ }^{1}$ The density of the perfluorinated liquids is very high. Most liquids will float in them.
} 


\subsubsection{Wash Solution [PF-5070 - 1 wt \% K157FS(M) or K157FS(L)]}

Taking a known quantity of diluent (described in Sect. 2.3.1), sufficient Krytox 157FS(M) or Krytox $157 \mathrm{FS}(\mathrm{L})^{2}$ was used to make a 1 -wt $\%$ solution. The results for a sample sent for analysis by uv indicated that its concentration was $0.95 \mathrm{wt} \%$, using the standard curve provided by ESI. (See Sect. 2.7 and the Appendix for details.)

\subsection{PREPARATION OF CONTAMINATED TEST PIECES}

\subsubsection{Washer Test Assemblies (WTAs)}

WTAs have been used in other tests at ESI and are considered a standardized test material. They consist of two or more washers separated by three to five 0.002 -in. stainless steel spacer washers and held together by a 0.25 -in. stainless steel bolt and nut. The test washers may be made of stainless steel, mild steel, or copper. One assembly of stainless steel washers (WTA-6) and one assembly of mild steel washers (WTA-3) were used in this series of tests. The overall dimensions are about 1.25 in. OD by about 0.75 in. tall.

\subsubsection{Mechanical Components}

Components from CRL Model 8 manipulator hands were obtained from the ORNL Plant and Equipment Division manipulator repair shop. The hands had been surveyed and packaged on November 7, 1991. A wrist assembly housing and gear (WL) were chosen for cleaning.

\subsubsection{Contamination of Test Assemblies and Manipulator Parts}

The WTAs were placed in Cell C (a beta-gamma hot cell ) in Building 3047 on March 1, 1993. They were moistened with water and placed on a contaminated high-efficiency particulate air filter in the cell. Periodically, they were moved about and rubbed on the filter. On March 11,

\footnotetext{
${ }^{2}$ Both surfactants are commercial mixtures of HFPO carboxylicacids made by the DuPont Company. The " $L$ " version has a lower molecular weight (2400 daltons) than the "M" (3900 daltons).
} 
1993, the WTAs were placed in a stainless steel tray and moistened with water. On April 6, 1993, cloth wiping rags, moistened with a commercial cleaner (Formula $409^{\mathrm{rm}}$ ) and used to decontaminate other objects, and thus contaminated with ${ }^{192} \mathrm{Ir}$ and ${ }^{191} \mathrm{Os}$, were inadvertently placed on top of the WTAs. On April 15, 1993, the WTAs were removed from the cell and placed in clean plastic bags for later use.

The manipulator hands and parts were contaminated in service. They had been partially decontaminated in 1991 with an ultrasonic treatment in water to remove alpha contamination and some beta-gamma contamination.

\subsection{PROCEDURE FOR DETERMINING THE LEVEL OF ULTRASONIC AGITATION}

The Branson 1200 ultrasonic cleaner has only one level of agitation. A piece of aluminum foil in water was essentially unchanged after $1 \mathrm{~min}$ of ultrasonic agitation. This unit was used only for preheating and degassing the rinse and wash solutions before each cleaning cycle.

The Crest unit has a dial to adjust the sweep frequency, with settings from about 0 to 9 . In $1 \mathrm{~min}$ at the highest setting (9), the test piece of aluminum foil was severely eroded and had developed many perforations of about $0.5 \mathrm{~mm}$ in size. This phenomenon indicates that the protective surface oxide film was being removed. At the 0 setting, a small amount of surface change was seen after $1 \mathrm{~min}$, but no perforations occurred. Intermediate values gave intermediate results in what appeared to be an orderly changing fashion. This unit was used for the cleaning cycles. In the early tests, a value of 5 was used, which was raised to 9 in later experiments.

\subsection{FILTRATION TESTS AND FLUID RECOVERY}

The residual liquid in the beakers after sonification and sampling was passed through a filter of either 0.1 - or $0.2-\mu \mathrm{m}$ pore size by gravity flow. The filtration rate was slow enough such that it 
was necessary to have more than one filtering unit in process at one time. Consequently, the designations of $F 1, F 2$, etc., are more for identifying them for analytical purposes than for placing them in the sequence of the cleaning tests.

\subsection{ANALYTICAL PROCEDURES}

\subsubsection{Radioactivity of Parts}

A semiquantitative measurement of initial and residual activity was made at the beginning and after each cleaning cycle using a Bicron "pancake" probe. The part was placed at the center of the probe face in about the same orientation for each measurement. The parts were analyzed using the automatic cycle, and counts were collected for $1 \mathrm{~min}$.

Initially and at selected times during each series of cleaning steps, the test piece was removed and nondestructively reanalyzed using the ORTEC. NOMAD germanium gamma detector system to estimate the amounts of activity remaining. Lack of full control of geometry ${ }^{3}$ and the effects of self-shielding limited the accuracy and precision of the results; however, it is believed that these measurements provided reasonable estimates of the total radioactivity (fixed and smearable) on the test pieces.

Standard smear techniques were used for determining the residual, transferrable contamination on the parts after selected cleaning cycles and at the end.

\subsubsection{Surfactant Concentration}

The analytical method of choice for determining surfactant concentration is uv analysis between about 200 and $220 \mathrm{~nm}$. The diluent is clear in this region. The spectra determined at ORNL are presented in Figs. A.1 and A.2, in the Appendix, along with a standardization curve

\footnotetext{
${ }^{3}$ The parts were large in comparison to the detector and were relatively close, as well, so that the "point source" assumption could not be used.
} 
provided by ESI for Krytox 157FS(M) (Fig. A.3). The surfactant has an active carboxyl group $(-\mathrm{COOH})$, which absorbs around $210 \mathrm{~nm}$. Krytox 157FS(L) has a lower molecular weight, yielding a higher concentration of $(-\mathrm{COOH})$ groups; therefore, the absorbance is higher for a 1 wt \% solution (Fig. A.2).

\subsubsection{Used or Recycled Diluent or Rinse Solution}

The radioactivity per volume of used, filtered liquid was estimated by impregnating two Whatman analytical filters, one with a 5-mL sample of composited filtered rinse and the other with a 5-mL sample of composited filtered wash solution, and allowing the volatile materials to evaporate. The dried filter papers were counted in a standard smear counter. Each had the same counting rate as background. A longer term count (1000 s) of both filters at one time in the NOMAD germanium detector gave no evidence of any peaks above the counter background.

A more precise measurement of residual activity after filtration was made by ORNL Analytical Cher.uistry Division personnel using procedure EPA-901.1.

\subsubsection{Filters}

The recovered filters were analyzed by a beta-gamma probe and by gamma scans. 


\section{EXPERIMENTAL EQUIPMENT}

\subsection{ULTRASONIC BATHS}

The following ultrasonic baths were used:

- Branson ultrasonic cleaner; model B-1200R-4, 5.5 in. long $\times 6$ in. wide $\times 4$ in. high, 0.5 -gal capacity, $80-\mathrm{W}$ sonification power, $150-\mathrm{W}$ heater, and digital control of temperature and sonification time.

- Crest model 4HT-710-3 ultrasonic bath having a fluid capacity of 3 gal and a cavity of $7 \times 10 \times 10$ in., and a 500-W heater. The ultrasonic power was provided by a model 4G250-3 ultrasonic generator, delivering $250-\mathrm{W}$ ultrasonic power at $40 \mathrm{kHz}$. The power supply has the capability of changing the sweep frequency by $10 \%$ using dial readings of 0 to 9 .

\subsection{FILTRATION EQUIPMENT}

The following filters and filter holders were used:

- Nylaflow filter membrane, $0.2-\mu \mathrm{m}$ pore size

- Durapore Type VV filter membrane, $0.1-\mu \mathrm{m}$ pore size

- Nalgene $250-\mathrm{mL}$ filter holder with $500-\mathrm{mL}$ receiver, model $300-4000$

- Nalgene $500-\mathrm{mL}$ filter holder with $1000-\mathrm{mL}$ receiver, model $300-4100$

- Nalgene 500-mL filter holder with funnel, model 310-4050

\subsection{ANALYTICAL MEASURING EQUIPMENT}

The following detectors and probes were used:

- Bicron Probe with Scaler, model Surveyor M, Geiger-Müller type, pancake gamma probe. 
- EG\&G Ortec NOMAD, a portable gamma spectrosopy system, model 92X-P with a highpurity germanium detector, model GEM-15190-P. It has a useful gamma-energy-detection capability of $40 \mathrm{keV}$ to $10 \mathrm{MeV}$. OMNIGAM(63) I3.02.27 software was used.

\subsection{OTHER EQUIPMENT}

Standard laboratory glassware (e.g., graduated cylinders, pipettes, and burettes) and equipment (e.g., laboratory balance) were used. 


\section{RESULTS}

\subsection{RUN 1, WTA-6}

The first run used a low-level contaminated washer test assembly, WTA-6 (made completely of stainless steel). As a low-activity sample, it was ideal for testing the procedures and the cleaning system while performing an actual set of cleaning cycles. It measured a net 2162 counts per minute (cpm) on the pancake beta-garnma probe (see Table 1). The run consisted of four cleaning cycles with rinse liquid, which were followed by three cleaning cycles using wash solution and then by a final cleaning cycle with rinse liquid.

The first four cycles of cleaning were performed with $150-\mathrm{mL}$ batches of preheated, degassed rinse liquid (PF-5070). After each cycle, the rinsed part was counted through a plastic petrie dish cover, using the pancake beta-gamma probe. After the fourth cleaning cycle, the part was taken to the NOMAD system for analysis, and the beta-gamma probe was moved from the hood to a far corner of the room to lower the background (see Table A.1, Appendix). After the fifth cleaning cycle using wash solution (1\% Krytox), it was discovered that significant blocking of the radiation ${ }^{4}$ was occurring in the relatively thick plastic petrie dish; therefore, future readings were made through thin plastic bags (Table A.2, Appendix). At this time, it was also discovered that the WTA had a higher probe reading when the bolt head was down (facing the probe surface) than when the screw end was down (lying at an angle on the probe surface); therefore, the orientation of the WTA was controlled for subsequent cleanings and measurements. In addition, several measurements were made and averaged for the results presented in the data-run tables (Table A.3, Appendix);

\footnotetext{
${ }^{4}$ The radiation that was blocked was assumed to be low-energy radiation.
} 
Table 1. Run data for WTA-6

Date: April 19, 20, 1993

Run number: 1 (WTA-6)

Test sample: WTA-6

Purpose of test: Procedure validation and training; measure removal with rinse and wash solutions Scan determined by E. S. Meyers

\begin{tabular}{|c|c|c|c|c|c|c|c|c|}
\hline \multirow{2}{*}{ Process step } & \multicolumn{8}{|c|}{ cycle number } \\
\hline & 1 & 2 & 3 & 4 & 5 & 6 & 7 & 8 \\
\hline Liquid, $\mathrm{R} / \mathrm{W}^{a}$ & $\mathbf{R}$ & $\mathbf{R}$ & $\mathbf{R}$ & $\mathbf{R}$ & W & W & w & $\mathbf{R}$ \\
\hline Volume, mL & 150 & 150 & 150 & 150 & 150 & 150 & 150 & 150 \\
\hline \multicolumn{9}{|l|}{ Degas } \\
\hline Time, $\min$ & 5 & 5 & 5 & 5 & 5 & 6 & 5 & 5 \\
\hline Temperature, ${ }^{\circ} \mathrm{C}$ & 40 & - & - & - & 54 & 41 & 56 & 58 \\
\hline \multicolumn{9}{|l|}{ Presoak } \\
\hline Time, $\min$ & 5 & 5 & 5 & 5 & 5 & 5 & 5 & 5 \\
\hline Temperature, ${ }^{\circ} \mathrm{C}$ & 56 & - & - & - & - & 50 & 50 & 50 \\
\hline \multicolumn{9}{|l|}{ Sweep } \\
\hline Frequency & 5 & 5 & 5 & 5 & 5 & 6.5 & 6.5 & 6.5 \\
\hline Time, $\min$ & 3 & 3 & 3 & 3 & 3 & 3 & 3 & 3 \\
\hline Temperature, ${ }^{\circ} \mathrm{C}$ & 56 & - & - & - & - & 50 & 50 & 50 \\
\hline \multirow{2}{*}{$\begin{array}{l}\text { Net activity, cpm, hd } \\
\text { pancake probe, } \mathrm{sd}^{c}\end{array}$} & 104 & - & - & 85 & 1069 & 225 & 407 & 278 \\
\hline & HD? & 28 & 11 & 42 & 226 & 149 & - & 37 \\
\hline $\mathrm{Ge}$ detector & & & & SURF ${ }^{d}$ & SURF & & SURF & SURF \\
\hline Scan ID.SPC & & & & 64 & 65 & & 67 & 68 \\
\hline Isotope, $\mathrm{Bq}$ & & & & & 286 & & & \\
\hline${ }^{191}$ Os & & & & 285 & $e$ & & 136 & 145 \\
\hline \multirow[t]{2}{*}{${ }^{192} \mathrm{Ir}$} & & & & 35 & & & $e$ & $e$ \\
\hline & & & & $6-4 /$ & & & & \\
\hline Liquid sample no. & $6-1$ & $6-2$ & $6-5$ & SURF & $6-5$ & $6-6$ & $6-7$ & $6-8$ \\
\hline Volume, mL & 5 & 5 & 5 & $6 \mathrm{~L} 14$ & 5 & 5 & 5 & 5 \\
\hline $\begin{array}{l}\text { Net activity, cpm } \\
\text { (pancake probe) }\end{array}$ & nd & nd & nd & $\begin{array}{l}51450 \\
\text { ndind }\end{array}$ & $n d^{\prime}$ & nd & nd & nd \\
\hline Filter no. & & & & $6 \mathrm{Fl}$ & & $6 \mathrm{~F} 2$ & & $6 \mathrm{~F} 3$ \\
\hline Net activity, cpm & & & & 459 & & 167 & & 114 \\
\hline \multirow[t]{2}{*}{ Isotope, $\mathrm{Bq}$} & & & & SURF & & SURF & & SURF \\
\hline & & & & $6 \mathrm{Fl}$ & & $6 \mathrm{~F} 2$ & & $6 \mathrm{~F} 2$ \\
\hline${ }^{191}$ Os & & & & 68 & & $e$ & & $e$ \\
\hline
\end{tabular}

Note: Cycles 1-4 were counted in petrie dish; cycles 5-8 were counted in plastic, not petrie dish.

${ }^{\sigma} \mathrm{R}=$ rinse; $\mathbf{W}=$ wash.

hd $=$ head down.

$c_{\text {sd }}=$ screw down.

${ }^{d}$ SURF = surfactant.

Values are presented as "less than" numbers.

$f_{\text {nd }}=$ not detected. 
WTA-6 was counted in the plastic bag after four cleanings with rinse liquid and one cleaning with wash solution. It measured a net $1109 \mathrm{cpm}$ on the pancake beta-gamma probe, indicating a decrease to about half the original count rate. Three additional cleaning cycles were provided two with wash solution and the final one with rinse liquid - to remove the Krytox. After these three treatments, the readings on the pancake beta-gamma probe had decreased to an average of about $300 \mathrm{cpm}$ for the three cycles.

The decrease in the residual activity, as measured by the probe, is presented in Fig. 1. The very low activity levels penetrating the plastic petrie dish are also shown. The only activities present in sufficient quantities to be measured by the germanium detector system were ${ }^{191}$ Os and

${ }^{192}$ Ir. The decreases in their activities are presented in Fig. 2 and Table 2.

The smear results for WTA- 6 after cycle 8 were 90 disintegrations per minute (dpm) on the bolt end, $250 \mathrm{dpm}$ between the washers, and $10 \mathrm{dpm}$ on the nut end.

About $450 \mathrm{~mL}$ of filtered, used rinse solution in a glass bottle (SURF6L14) was analyzed by the NOMAD system; no peaks above background were found.

\subsection{RUN 2, WTA-3}

The second run used the highest level of the contaminated WTA-3 (with large washers of mild steel). The first part of Run 2 followed the pattern of four cleaning cycles with rinse liquid, followed by three cleaning cycles of wash liquid, and a final rinse cycle. WTA-6 was disassembled and given two more cleaning cycles, one with wash and one with rinse liquid.

WTA-3 had two mild steel washers, and all the other components were stainless steel. Its initial reading was a net $20,467 \mathrm{cpm}$ on the pancake beta-gamma probe with the bolt head down (facing the probe surface), and $7072 \mathrm{cpm}$, up (lying at an angle on the probe surface) through the plastic bag. The run data for WTA-3 are presented in Table 3. 


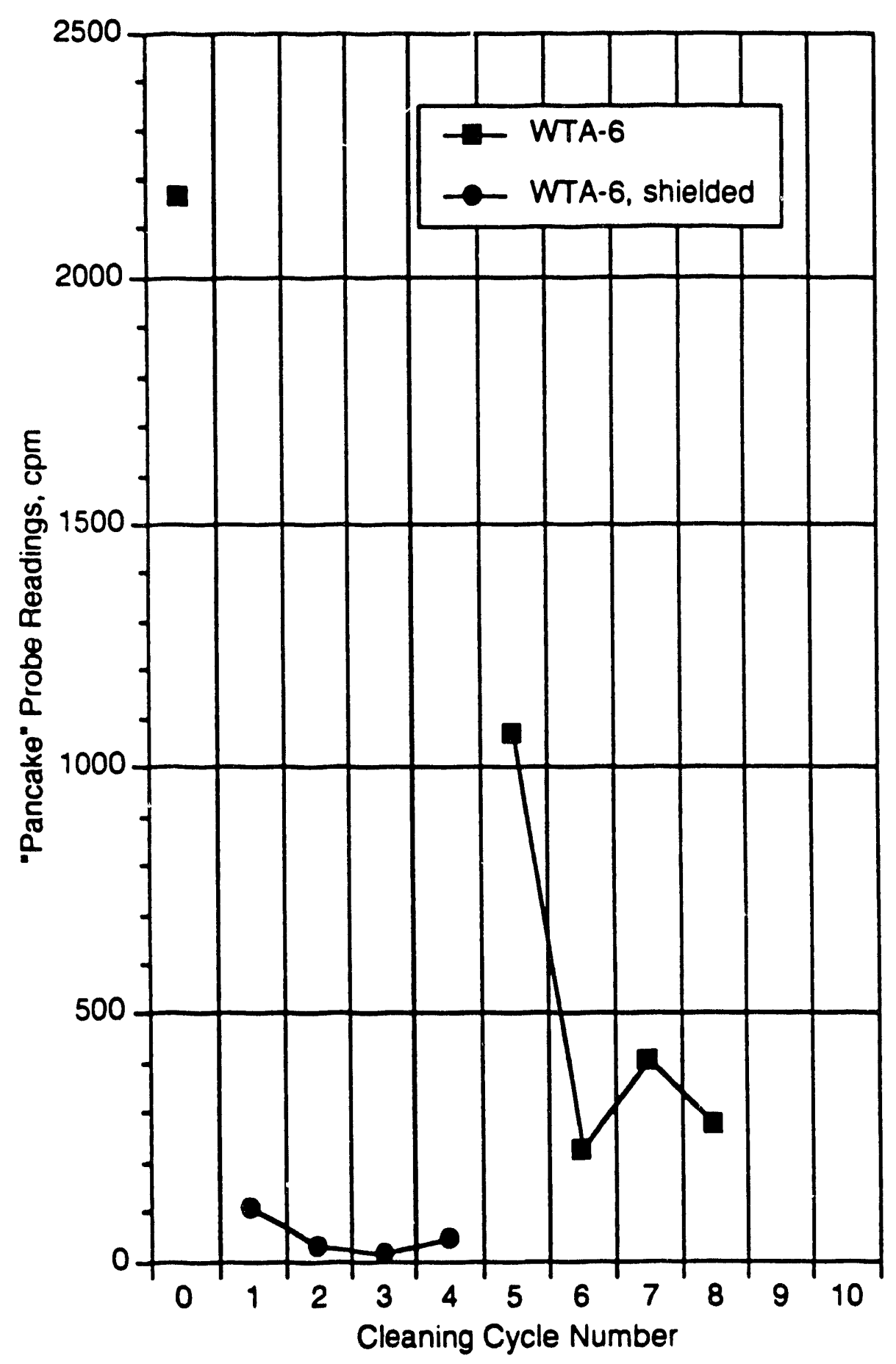

Fig. 1. Decontaminating WTA-6 (pancake probe readings). 


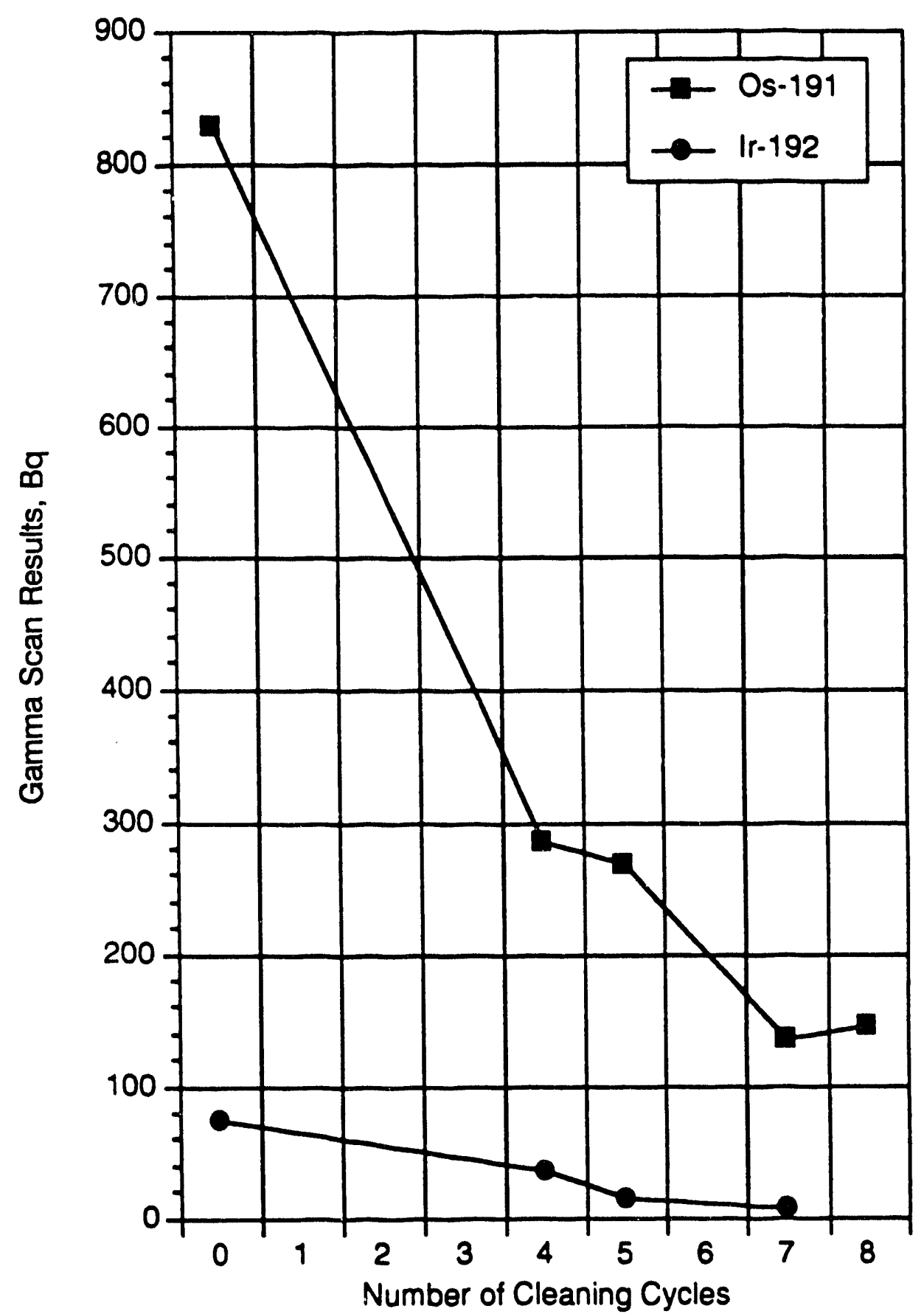

Fig. 2. Decontamination of WTA-6. 
Table 2. Gamma scan data for WTA-6

\begin{tabular}{|c|c|c|c|c|c|c|c|c|c|}
\hline \multirow[b]{2}{*}{$\begin{array}{l}\text { Sample ID } \\
\text { specimens }\end{array}$} & \multirow[b]{2}{*}{ Description } & \multicolumn{2}{|c|}{ Probe data (cpm) } & \multicolumn{6}{|c|}{ Germanium detector data ${ }^{a}(\mathrm{~Bq})$} \\
\hline & & $\begin{array}{c}\text { Beta-gamma } \\
\text { head down }\end{array}$ & $\begin{array}{l}\text { Beta-gamma } \\
\text { screw down }\end{array}$ & ${ }^{60} \mathrm{Co}$ & ${ }^{137} \mathrm{Cs}$ & ${ }^{152} \mathrm{Eu}$ & ${ }^{154} \mathrm{Eu}$ & ${ }^{191} \mathrm{Os}$ & ${ }^{192} \mathrm{Ir}$ \\
\hline \multicolumn{10}{|c|}{ Probed through a plastic bag } \\
\hline SURF6. SPC & Initial scan WTA-6 & 2162 & orientation? & $<115$ & $<47$ & $<64$ & $<107$ & 829 & 74 \\
\hline \multicolumn{10}{|c|}{ Probed through a petrie dish } \\
\hline & After cycle 1 & 104 & & & & & & & \\
\hline & After cycle 2 & 28 & & & & & & & \\
\hline & After cycle 3 & & 11 & & & & & & \\
\hline & After cycle 4 & 85 & & & & & & & \\
\hline SURF64.SPC & After cycles $1-4$ & 85 & 42 & $<78$ & $<10$ & $<88$ & $<53$ & 285 & 35 \\
\hline SURF65.SPC & After cycle 5 & 84 & 32 & $<7$ & $<6$ & $<70$ & $<32$ & 268 & $<15$ \\
\hline \multicolumn{10}{|c|}{ Probed through a plastic bag } \\
\hline & After cycle 5 & 1109 & 225 & & & & & & \\
\hline & After cycle 6 & $2 \approx 5$ & 149 & & & & & & \\
\hline SURF67.SPC & After cycle 7 & 366 & & $<9$ & $<2$ & $<44$ & $<94$ & 136 & $<7$ \\
\hline SURF68.SPC & After cycle 8 & 278 & 37 & $<10$ & $<21$ & $<41$ & $<36$ & 145 & $<62$ \\
\hline SURF6F1.SPC & Filter after cycles $1-4$ & 459 & & $<10$ & $<9$ & $<57$ & $<20$ & 68 & $<7$ \\
\hline SURF6F2.SPC & Filter after cycles 5-6 & 167 & & $<38$ & $<7$ & $<45$ & $<26$ & $<29$ & $<80$ \\
\hline SURF6F3.SPC & Filter after cycles 7-8 & 114 & & $<41$ & $<24$ & $<20$ & $<13$ & $<10$ & $<34$ \\
\hline SURF6L12.SPC & Filtrate from cycles $1-4$ & (450) not detected & & $<11$ & $<2$ & $<54$ & $<94$ & $<12$ & $<3$ \\
\hline SURF61.SPC & Sample cycle 1 liquid & $(5 \mathrm{~mL})$ not detected & & $<16$ & $<8$ & $<7$ & $<10$ & $<18$ & $<5$ \\
\hline
\end{tabular}

\footnotetext{
${ }^{a}$ All gamma scans made through plastic bag.
} 
Table 3. Run data for WTA-3

\begin{tabular}{|c|c|c|c|c|c|c|c|c|c|c|}
\hline \multirow[b]{2}{*}{ Process step } & \multicolumn{10}{|c|}{ Cycle number } \\
\hline & 1 & 2 & 3 & 4 & 5 & 6 & 7 & 8 & $9^{a}$ & $10^{a}$ \\
\hline Liquid $(R / W)^{b}$ & $\mathbf{R}$ & $\mathbf{R}$ & $\mathbf{R}$ & $\mathbf{R}$ & $\mathbf{w}$ & $\mathbf{w}$ & $\mathbf{w}$ & $\mathbf{R}$ & $\mathbf{w}$ & $\mathbf{R}$ \\
\hline Volume, $\mathrm{mL}$ & 150 & 150 & 150 & 150 & 150 & 150 & 150 & 150 & 200 & 200 \\
\hline $\begin{array}{l}\text { Degas } \\
\text { Time, min. } \\
\text { Temperature, }{ }^{\circ} \mathrm{C}\end{array}$ & $\begin{array}{r}5 \\
62\end{array}$ & $\begin{array}{r}5 \\
62\end{array}$ & $\begin{array}{l}>15 \\
60\end{array}$ & 62 & 62 & $61^{5}$ & $\begin{array}{r}5 \\
61\end{array}$ & $\begin{array}{r}5 \\
58\end{array}$ & $\begin{array}{r}7 \\
60\end{array}$ & $\begin{array}{r}5 \\
60\end{array}$ \\
\hline $\begin{array}{l}\text { Presoak } \\
\text { Time, min. } \\
\text { Temperature, }{ }^{\circ} \mathrm{C}\end{array}$ & $\begin{array}{r}5 \\
50\end{array}$ & $\begin{array}{r}5 \\
50\end{array}$ & $\begin{array}{l}5 \\
-\end{array}$ & 5 & $\begin{array}{l}22 \\
50\end{array}$ & 5 & $\begin{array}{r}5 \\
50\end{array}$ & $\begin{array}{r}5 \\
50\end{array}$ & $\begin{array}{l}20 \\
-\end{array}$ & 5 \\
\hline $\begin{array}{l}\text { Sweep } \\
\text { Frequency } \\
\text { Tim:, min. } \\
\text { Temperature, • C }\end{array}$ & $\begin{array}{c}5 \\
3 \\
50\end{array}$ & $\begin{array}{r}5 \\
5 \\
50\end{array}$ & $\begin{array}{r}5 \\
3 \\
50\end{array}$ & $\begin{array}{r}5 \\
3 \\
50\end{array}$ & $\begin{array}{r}5 \\
3 \\
50\end{array}$ & $\begin{array}{r}5 \\
3 \\
50\end{array}$ & $\begin{array}{r}5 \\
3 \\
50\end{array}$ & $\begin{array}{r}5 \\
3 \\
50\end{array}$ & $\begin{array}{l}5 \\
3 \\
-\end{array}$ & $\begin{array}{l}5 \\
3 \\
-\end{array}$ \\
\hline $\begin{array}{l}\text { Net activity, } \\
\text { cpm, hd }{ }^{c}\end{array}$ & 2934 & 2402 & 2799 & 2835 & 1916 & 2071 & 1800 & 1635 & $\cdot$ & 820 \\
\hline Pancake probe, $\mathrm{sd}^{d}$ & 1312 & 1211 & 1078 & 1050 & 825 & - & 552 & 444 & $\cdot$ & 362 \\
\hline $\begin{array}{l}\text { Ge detector } \\
\text { Scan ID.SFC }\end{array}$ & & & & $\begin{array}{c}\text { SURFe } \\
34\end{array}$ & & & $\begin{array}{c}\text { SURF } \\
37\end{array}$ & $\begin{array}{c}\text { SURF } \\
38\end{array}$ & & $\begin{array}{c}\text { SURF } \\
310\end{array}$ \\
\hline $\begin{array}{l}\text { Isotopes, Bq } \\
{ }^{60} \mathrm{Co} \\
{ }^{137} \mathrm{Cs} \\
{ }^{152} \mathrm{Eu} \\
{ }^{154} \mathrm{Eu} \\
{ }^{191} \mathrm{Os} \\
{ }^{192} \mathrm{Ir}\end{array}$ & & & & $\begin{array}{c}107 \\
f \\
f \\
f \\
f \\
f\end{array}$ & & & $\begin{array}{l}f \\
f \\
f \\
f \\
f \\
f\end{array}$ & $\begin{array}{l}f \\
f \\
f \\
f \\
f \\
f\end{array}$ & & $\begin{array}{l}f \\
f \\
f \\
f \\
f \\
f\end{array}$ \\
\hline Liquid sample no. & $3-1$ & $3-2$ & $3-3$ & $3-4$ & 3.5 & $3-6$ & $3-7$ & $3-8$ & $3-9$ & $3-10$ \\
\hline Volume, mL & 5 & 5 & 5 & 5 & 5 & 5 & 5 & 5 & 5 & 5 \\
\hline $\begin{array}{l}\text { Net activity, } \\
\text { cpm }\end{array}$ & 68 & nd8 & nd & nd & nd & nd & nd & nd & nd & nd \\
\hline Filter no. & & & & $3 F 1$ & & $\begin{array}{l}3 F 2 \\
\text { here? }\end{array}$ & & $\begin{array}{l}3 F 3 \\
\text { here? }\end{array}$ & & $3 F 4$ \\
\hline $\begin{array}{l}\text { Net activity, } \\
\text { cpm }\end{array}$ & & & & 4909 & & 957 & & 91 & & 603 \\
\hline Isotope, Bq & & & & & & & & & & \\
\hline${ }^{60} \mathrm{Co}$ & & & & 704 & & 182 & & $f$ & & 238 \\
\hline
\end{tabular}

${ }^{\text {aseparated. }}$

$b_{R}=$ rinse; $W=$ wash.

$c_{\text {hd }}=$ head down.

$d_{\text {sd }}=$ screw down

'SURF = surfactant.

fValues are given as "less than" numbers.

8 nd $=$ not detected. 
The first four cleaning cycles were performed with rinse liquid. The cleaning was continued using wash solution for cycles 5 through 7 . Because the beta-gamma probe of radiation levels remained relatively high, WTA-3 was disassembled, and the parts were hung on wires in the beaker. One additional cycle of cleaning and one cycle of rinse were performed using $200 \mathrm{~mL}$ of solution - in each case further reducing the residual radioactivity.

Because of the relatively slow filtration by gravity, it was occasionally necessary to add the used cleaning liquid to an empty filter housing while a previous one was emptying. Thus, the placement of the filters in Tables 2 and 3 is somewhat misleading - the filters are identified for sampling purposes rather than for sequence in the run cycles. The final two batches of liquids were passed through the final filter, $3 \mathrm{~F} 4$.

A steep drop in the probe reading was found for the first cycle, followed by a nearly constant residual readings for the remaining three cycles of rinse liquid. A steady drop in residual activity was observed for the subsequent steps (Fig. 3). Run 1 data are superimposed on the graph. Although the values for cycles 2,3, and 4 are not plotted because of the shielding of the petrie dish in Run 1, there is qualitative similarity in the later cycles. Gamma scan results for Run 2 are presented in Fig. 4 and Table 4.

The smear results for WTA-3 were $340 \mathrm{dpm}$ for the bolt end, $70 \mathrm{dpm}$ between the washers, and $80 \mathrm{dpm}$ at the nut end.

\subsection{RUN 3, MANIPULATOR WRIST HOUSING (WL)}

The third run used a contaminated wrist housing assembly from the slave end (in-cell part) of a manipulator hand. It consisted of three cleaning cycles with wash solution, followed by a cleaning cycle with rinse liquid. It was disassembled and given a longer cleaning cycle (in three stages) in wash solution; washing was followed by manual rinsing. 


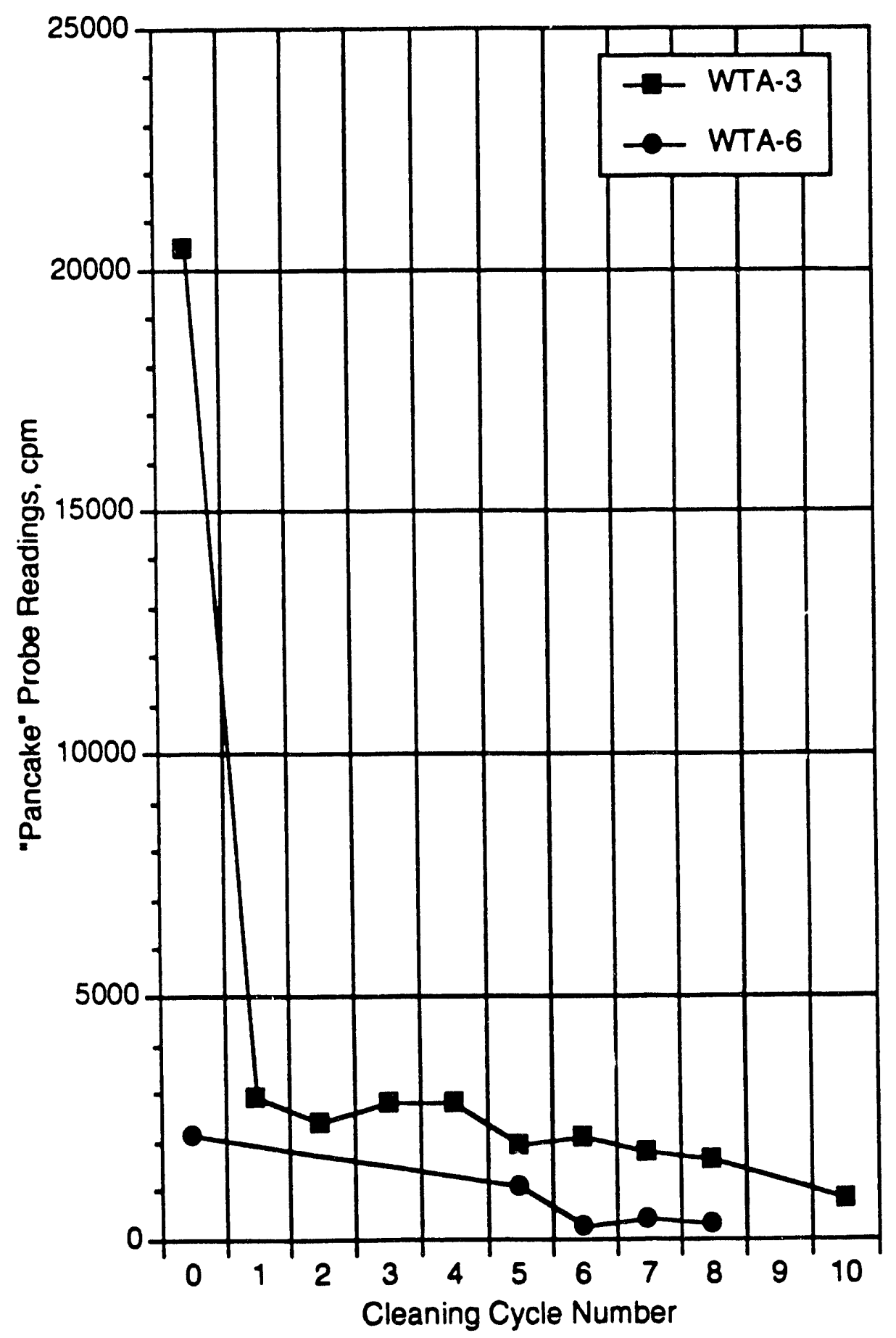

Fig. 3. Decontaminating WTAs 3 and 6 (pancake probe readings). 


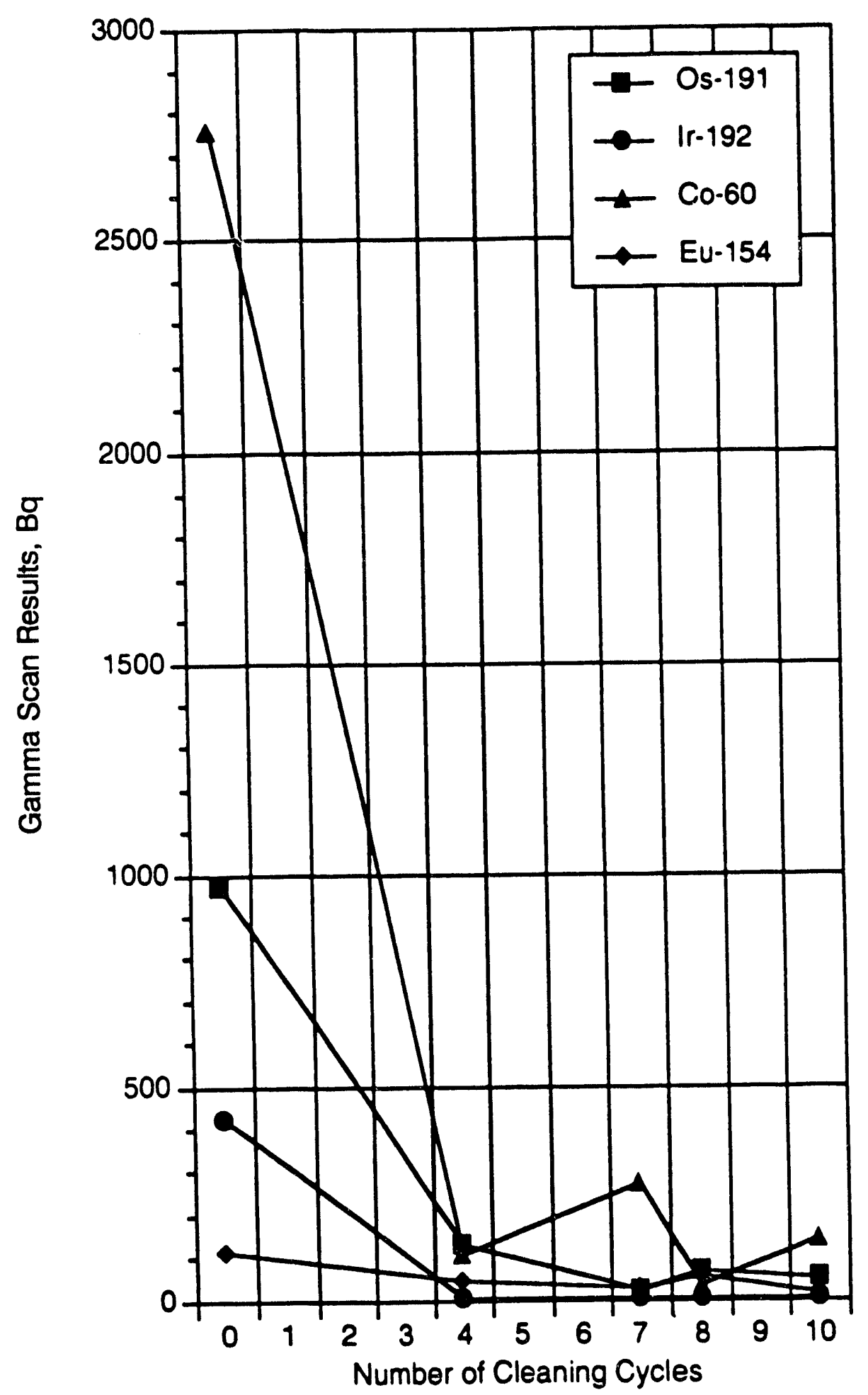

Fig. 4. Cleaning of WTA-3. 
Table 4. Gamma scan data for WTA-3

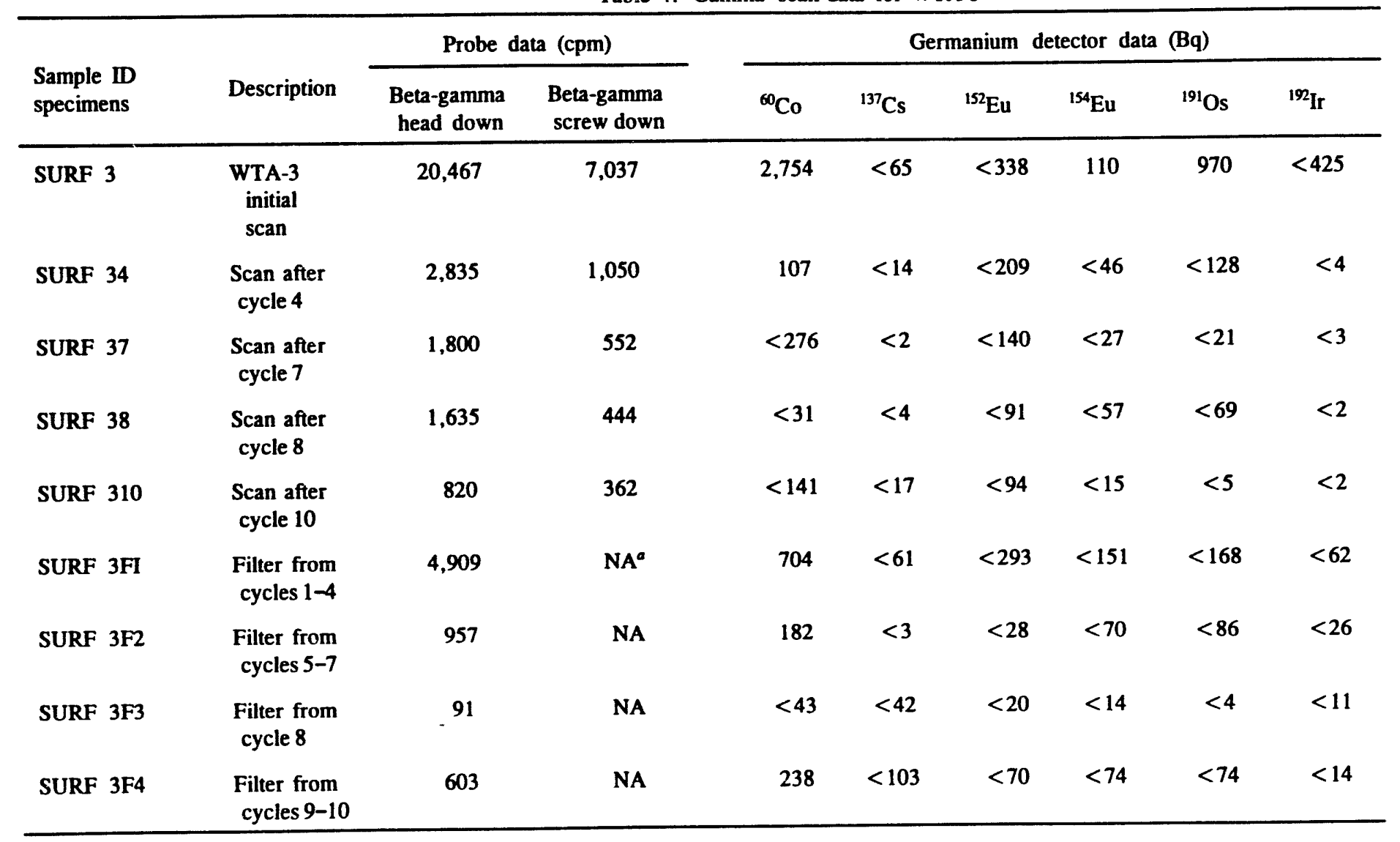

${ }^{\top} \mathrm{NA}=$ not applicable. 
The left half of a manipulator wrist housing chosen for Run 3 was a dull black color on the outside, a color typical of anodized aluminum. On the inside, it was a dull aluminum color. The inner side of the wrist assembly had a circular bearing race (without bearing) containing some black "crud" - probably leftover lubricant. ${ }^{6}$ Near this place was a gear and a washer affixed to the housing by a screw coming from the outside. The gear had some "crud" near it also, and it turned relatively stiffly. It loosened up after cleaning. The master end of the housing had two "ears" attached with screws. The radiation levels were quite high relative to the WTA parts, reading over $62,000 \mathrm{cpm}$ on the pancake beta-gamma probe, and were at maximum levels on the outside surface in the vicinity of the screw holding the gear. ${ }^{7}$ Because the housing assembly was too long for the $600-\mathrm{mL}$ beaker, each cleaning cycle was done in two steps. The part was inverted between steps.

The run data for WL are presented in Table 5.

After the first cycle, the wash solution on the filter looked somewhat turbid, and small flakes of "paint" were seen floating in it. In the first half-cycle of the second wash, the sweep frequency level was raised to 6 (from 5); and in the second half-cycle, to 7. The "crud" did not seem to be removed from the bearing circle. After the second cycle with wash solution, the part was smeared. One smear (No. 1, 21,820 dpm) caught some of the black "crud"; the other (No. 2, 5330 dpm) was "crud" free. The sweep frequency level was raised to 9 , the highest value, for the third cycle with wash solution. The fourth cycle was performed with rinse solution. After the fourth

\footnotetext{
${ }^{5}$ Determined by facing the manipulator hand from the front.

${ }^{6}$ The manipulator shop identified their radiation-resistant lubricant as Chevron NRRG 235.

${ }^{7}$ While the initial part was smeared before it was placed in the hood, the smear results were not recorded. However, the health physicist recalled that the smear read $2400 \mathrm{dpm}$ on the smear counter. It was not known if that smear had "crud" on it.
} 
Table 5. Run data for manipulatory wrist housing (WL)

\begin{tabular}{|c|c|c|c|c|c|c|c|}
\hline \multirow[b]{2}{*}{ Process step } & \multicolumn{6}{|c|}{ Cycle number } & \multirow{2}{*}{$\begin{array}{c}\text { After } \\
\text { disassembly } \\
\text { (housing } \\
\text { only) }\end{array}$} \\
\hline & 1 & 2 & 3 & 4 & 5 & 6 & \\
\hline Liquid $(\mathrm{R} / \mathrm{W})^{a}$ & $w$ & w & $w$ & $\mathbf{R}$ & $w$ & $w$ & \\
\hline Volume, $\mathrm{mL}$ & 300 & 350 & 350 & 350 & 500 & 500 & \\
\hline \multicolumn{8}{|l|}{ Degas } \\
\hline Time, $\min$ & $>5$ & 5 & 5 & 5 & 15 & $>5$ & \\
\hline Temperature, ${ }^{\circ} \mathrm{C}$ & $\begin{array}{l}\min \\
60\end{array}$ & 60 & 60 & 62 & 60 & 60 & \\
\hline \multicolumn{8}{|l|}{ Presoak } \\
\hline Time, $\min$ & $20 / 20$ & $3 / 4.5$ & $5 / 5$ & $1 / 1$ & 3 & 20 & \\
\hline Temperature, ${ }^{\circ} \mathrm{C}$ & 55 & 50 & 50 & 50 & 50 & 50 & \\
\hline \multicolumn{8}{|l|}{ Sweep } \\
\hline Frequency & 5 & $6 / 7$ & 9 & 9 & 5.9 & 9 & \\
\hline Time, min & $3 / 3$ & $3 / 3$ & $3 / 3$ & 313 & 3 & 10 & \\
\hline Temperature, ${ }^{\circ} \mathrm{C}$ & 52 & 50 & 50 & 50 & 50 & 50 & \\
\hline Net activity, cpm & 52,868 & 61,465 & 59.956 & 60,414 & 60.572 & 48,738 & 56,036 \\
\hline pancake probe & 12.799 & 11,342 & 9,892 & 8.717 & 8.738 & 7,855 & 9,604 \\
\hline \multicolumn{8}{|l|}{$\begin{array}{l}\text { Smear activity, cpm } \\
\text { Outside }\end{array}$} \\
\hline (black) & - & - & - & 220 & 470 & 590 & \\
\hline $\begin{array}{l}\text { Inside } \\
\text { (shiny) }\end{array}$ & . & - & . & 5,130 & 3,660 & 710 & \\
\hline Ge detector scan & & SURFWL2 ${ }^{b}$ & & SURFWLA & SURFWLS & SURFWLG & \\
\hline Isotope, Bq & & & & & & & \\
\hline${ }^{60} \mathrm{Co}$ & & 49,805 & & 39,860 & 47,994 & 45,074 & \\
\hline${ }^{152.154} \mathrm{Eu}$ & & 55,865 & & 47,539 & 31,591 & 30.364 & \\
\hline Liquid sample no. & LW-1 & LW.2 & LW-3 & $L W-4$ & LW-5 & LW-6 & \\
\hline Volume, $\mathrm{mL}$ & 5 & 5 & 5 & 5 & 5 & 5 & \\
\hline Filter no. & & & WLF-1 & & WLF-2 & WLF-3 & \\
\hline $\begin{array}{l}\text { Net activity, } \\
\mathrm{cpm}\end{array}$ & & & 8,673 & & 18,155 & 2.199 & \\
\hline Isotopic activity, Bq & & & SURFWLF1 & & SURFWLF & SURFWLF & \\
\hline${ }^{60} \mathrm{Co}$ & & & 126 & & 2 & 3 & \\
\hline${ }^{152} \mathrm{Eu},{ }^{154} \mathrm{Eu}$ & & & 850 & & 2,466 & 304 & \\
\hline & & & & & 3.751 & 699 & \\
\hline
\end{tabular}

${ }^{2} R=$ rinse; $W=$ wash.

bSURF = surfactant. 
cycle, the aluminum looked brighter, and it appeared that the "crud" might have been loosened. The gear rotated freely. The housing was smeared inside $(5130 \mathrm{dpm})$, outside $(220 \mathrm{dpm})$, and gear and hole $(0 \mathrm{dpm})$. Cycle 5 used a combination of $300 \mathrm{~mL}$ of original wash solution and 200 $\mathrm{mL}$ of freshly prepared Krytox $157 \mathrm{FS}(\mathrm{L})$ solution $(33.80 \mathrm{~g} / 1760 \mathrm{~mL}$ total liquid). The part was removed from the beaker, rinsed with a wash solution, rinsed again by rinse solution, and bagged for storage overnight.

The wrist housing assembly was taken apart prior to cycle 6. The "ears" were removed and counted with the screws (net $4897 \mathrm{cpm}$ with the outside and $1251 \mathrm{cpm}$ with the inside facing the probe). The gear and split (C) retainer ring were removed. The gear mounting post and matching area on the housing, which became exposed when the gear mounting post was removed, showed an uneven corrosion and a yellowish-whitish discoloration. The radiation readings of the gear mounting post and nut were a net $5207 \mathrm{cpm}$ outside and $3314 \mathrm{cpm}$ inside. The wrist housing, without the removable parts, read about $56,180 \mathrm{cpm}$ outside and about $9600 \mathrm{cpm}$ inside.

The nut, gear, and ears were threaded on a wire for cleaning. The housing rested on the bottom of the beaker. Enough wash solution was added to make $500 \mathrm{~mL}$, an amount sufficient to cover the parts. The 3-min sonification seemed to be raising bubbles from the housing (shiny side) but not from the other parts or the outside surfaces. ${ }^{8}$ The housing was inverted, and all parts were given another 3-min treatment, followed by another 4-min treatment. The parts were removed, and each was given a manual rinse before packaging in plastic bags. The wrist housing read about $48,740 \mathrm{cpm}$ outside and about $7860 \mathrm{cpm}$ inside on the pancake beta-gamma probe.

The progress of the decontamination is shown in Fig. 5. The probe results showed very little change until the wrist assembly was disassembled; then decontamination proceeded. The gamma

\footnotetext{
${ }^{8}$ After cleaning, the inside was bright and shiny. It looked as if the cleaning treatment at a sweep frequency level of 9 had roughened the surface. There were several small, aluminum-colored filings in the bottom of the beaker. The anodized side did not appear to change during the treatment, although some flakes of "paint" were seen on the filter.
} 


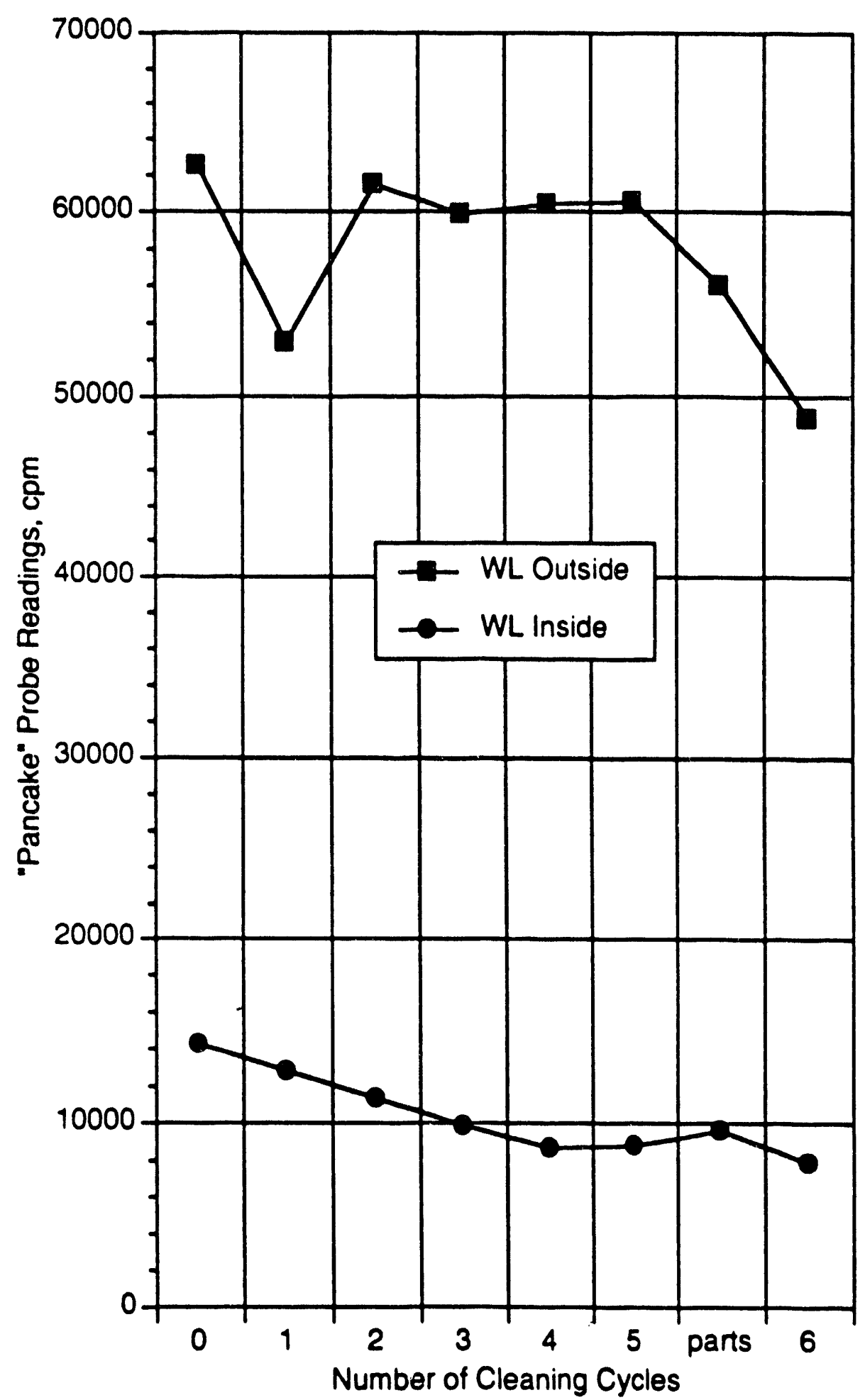

Fig. 5. Decontaminating a manipulator wrist housing (WL) pancake probe readings. Note: The initial points $(0$ cycles) are maxima, not averages. 
scans showed steady decreases of ${ }^{60} \mathrm{Co}$ and ${ }^{152,154} \mathrm{Eu}^{9}$ (Fig. 6 and Table 6). The smear data for WL are presented in Table 7. This more complex piece was smeared after cleaning steps $2,4,5$, and 6. Between steps 5 and 6 , the WL was taken apart. A smear of all surfaces, including the "crud" in the holes, read nearly $22,000 \mathrm{dpm}$ after two cycles of cleaning. The data from the smears taken after cycle 6 range from about 590 to $710 \mathrm{dpm}$ - if the "crud" is omitted.

A $100-\mathrm{mL}$ sample of wash filtrate from test specimen WL, which was filtered through a $0.2-\mu \mathrm{m}$ filter by gravity, was analyzed by the ORNL Low-Level Radiochemical Analysis Laboratory. The results were $33 \pm 5 \mathrm{~Bq} / \mathrm{L}{ }^{60} \mathrm{Co}, 43 \pm 22 \mathrm{~Bq} / \mathrm{L}{ }^{152} \mathrm{Eu}, 40 \pm 11 \mathrm{~Bq} / \mathrm{L}{ }^{154} \mathrm{Eu}$, and 0.3 $\pm 2.0 \mathrm{~Bq} / \mathrm{L}{ }^{191} \mathrm{Os}$. These values are about three orders of magnitude lower ${ }^{10}$ than specified in the ORNL Health Physics Manual for reuse of liquids not intended for human consumption.

\footnotetext{
${ }^{9}$ The peaks for ${ }^{152} \mathrm{Eu}$ and ${ }^{154} \mathrm{Eu}$ were very close together, and the NOMAD system had difficulty distinguishing them. On the advice of E. S. Meyers, they were added together to get the values in the table and plotted in this figure.

${ }^{10} \mathrm{The}$ values given are $18 \mathrm{~Bq} / \mathrm{mL}$ for ${ }^{60} \mathrm{Co}, 22 \mathrm{~Bq} / \mathrm{mL}$ for ${ }^{152} \mathrm{Eu}, 74 \mathrm{~Bq} / \mathrm{mL}$ for ${ }^{191} \mathrm{Os}$, and $15 \mathrm{~Bq} / \mathrm{mL}$ for ${ }^{192} \mathrm{Ir}$.
} 


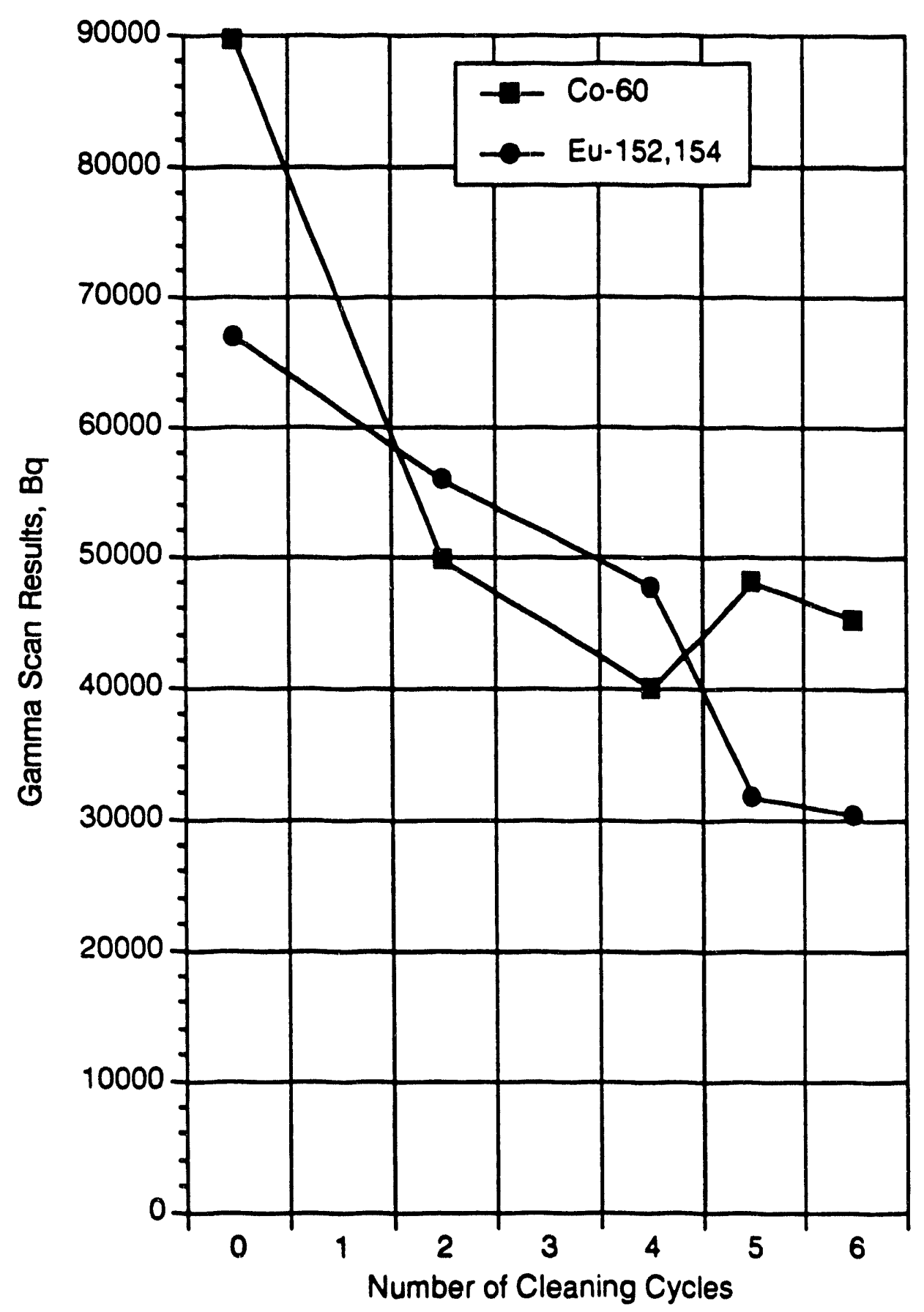

Fig. 6. Decontamination of a manipulator wrist housing. Note: Housing disassembled after cycle 5. All ${ }^{60} \mathrm{Co}$ peaks had bad shape for cycle 5 . 
Table 6. Gamma scan data manipulator wrist housing (WL)

\begin{tabular}{|c|c|c|c|c|c|c|c|c|}
\hline \multirow[b]{2}{*}{$\begin{array}{l}\text { Sample ID } \\
\text { specimens }\end{array}$} & \multirow[b]{2}{*}{ Description } & \multicolumn{2}{|c|}{ Probe data (cpm) } & \multicolumn{5}{|c|}{ Germanium data detector (Bq) } \\
\hline & & $\begin{array}{c}\text { Beta-gamma } \\
\text { outside }\end{array}$ & $\begin{array}{c}\text { Beta-gamma } \\
\text { inside }\end{array}$ & ${ }^{60} \mathrm{Co}$ & ${ }^{137} \mathrm{Cs}$ & $\begin{array}{l}{ }^{152} \mathrm{Eu}, \\
{ }^{154} \mathrm{Eu}\end{array}$ & ${ }^{191}$ Os & ${ }^{192} \mathbf{I r}$ \\
\hline \multicolumn{9}{|c|}{$\begin{array}{l}\text { Outside is black anodized } \\
\text { Inside is aluminum colored }\end{array}$} \\
\hline SURFWL & WL, initial scan & 62,567 & 14,333 & 89,544 & $<571$ & 66,916 & $<395$ & $<459$ \\
\hline SURFWL2 & Scan after cycle 2 & 61,465 & 11,342 & 49,805 & $<1,150$ & 55,865 & $<218$ & $<165$ \\
\hline SURFWL4 & Scan after cycle 4 & 60,414 & 8,717 & 39,860 & $<844$ & 47,539 & $<409$ & $<34$ \\
\hline SURFWL5 & Scan after cycle 5 & 60,572 & 8,738 & 47,994 & $<1,320$ & 31,591 & $<326$ & $<600$ \\
\hline SURFWL6 & Scan after cycle 6 & 55,376 & 9,604 & 45,074 & $<551$ & 30,364 & $<218$ & $<216$ \\
\hline SURFWL2 & Smear from cycle 2 & & & 319 & $<66$ & 386 & $<32$ & $<6$ \\
\hline SURFWLF1 & Filter from cycles 1 and 2 & 8,673 & & 126 & $<10$ & 850 & $<67$ & $<64$ \\
\hline SURFWLF2 & Filter from cycles 3 and 4 & 18,155 & & 2,466 & $<165$ & 3,751 & $<103$ & $<36$ \\
\hline SURFWLF3 & Filter from cycles 5 and 6 & 2,199 & & 304 & $<7$ & 699 & $<12$ & $<13$ \\
\hline
\end{tabular}


Table 7. Smear data for the disassembled manipulator housing (WL), Run 3 (in disintegrations per minute per $100 \mathrm{~cm}^{2}$ )

\begin{tabular}{lrrrr}
\hline & \multicolumn{4}{c}{ Cycle } \\
\cline { 2 - 5 } $\begin{array}{c}\text { Part smeared } \\
\text { after cycle }\end{array}$ & 2 & 4 & 5 & 6 \\
\hline All surfaces & 21,820 & & & \\
Without holes & 5,330 & & 570 & 590 \\
Black side & 220 & 3,660 & 710 \\
Shiny side & 5,130 & & \\
Gear and hole & 50 & 3,730 & 2,380 \\
Crud & & 37,440 \\
Nut & & 200 \\
Gear & & & \\
\hline
\end{tabular}




\section{DISCUSSION}

The procedure for contaminating the WTAs allowed for the possible formation of fixed contamination in addition to particulates. The exposure of the WTAs to Cell 3 atmosphere and rubbing around on the used filters in the cell provided surface contamination by particulates containing radioactive species. However, the periodic wetting of the samples may have caused some of the radioactive materials to go into solution on the surface, perhaps reacting with the surfaces or drying out in nonparticulate forms. Furthermore, the unintended placement of wipes contaminated with Os, Ir, and U and containing unknown amounts of water and "409"cleaning agents may also have led to contamination of surfaces by nonparticulate species.

The consequences of these events should provide a more challenging cleaning environment, but they may also have taken the tests outside of regions where the ESI process is known to be effective.

\subsection{RUN 1, WTA-6}

WTA-6, which was chosen for the first experiment as a low activity sample, proved to be ideal to test our procedures and system while performing an actual set of cleaning cycles. The low activity levels provided some assurance that any unforeseen events would have minor consequences. The data, however, provided some initial information. For example, the betagamma probe, which was initially located in the same hood where the experiments were performed, suffered from too high a background $(213 \pm 16 \mathrm{cpm})$ to be useful as a qualitative estimate of cleaning effectiveness, and it was moved to a far corner of the decontamination room for the subsequent runs. Likewise, the effects of shielding by the plastic petrie dish and the importance of the placement and orientation of the sample on the beta-gamma probe were discovered. 
Referring to the decrease in residual activity, presented graphically in Fig. 1, it was found that the probe readings decreased after the first treatment with rinse liquid and stayed low for the next three treatments. The plastic petrie dish absorbed essentially all the beta and any very low energy gamma components, ${ }^{11}$ rendering the initial series of four measurements difficult to interpret as absolute measures of total cleaning effectiveness. Qualitatively, however, there seemed to be little net change with subsequent treatments using the rinse liquid (PF-5070), thus indicating that the bulk of a:y cleaning action had been performed in the first cleaning cycle. Taking the probe reading prior to cycle 5 (counted in a plastic bag), one calculates that about $50 \%$ of the initial activity was removed in the four washings in rinse liquid. The removal increased to $\mathbf{2 8 5 \%}$ after the additional three cycles of wash solution (1\% Krytox in PF-5070) followed by a final rinse.

Many of the specific radioactive isotopes measured by the NOMAD system and presented in Table 2 are shown as "less than" numbers, implying that these are, at best, upper limits. All the reported values were plotted in Fig. 2, showing the decrease in residual amounts of specific isotopes. Except for ${ }^{191}$ Os and ${ }^{192} \mathrm{Ir}$, the curves shown represent upper limits for the stated isotopes and do not represent accurate measurements. Using ${ }^{191}$ Os as the tracer, the decontamination was $260 \%$ in the first four cycles and rose to $280 \%$ at the end. Using ${ }^{192} \mathrm{Ir}$, the decontamination achieved in the first four treatments was $250 \%$, but the rest of the values were below the detection sensitivity. The results of the scans in measuring the decontamination are consistent with those based on the probe data. This degree of decontamination was accomplished in about $24 \mathrm{~min}$ of total treatment time.

\footnotetext{
"A crude estimate of shielding was made by ratio of the probe readings through the petrie dish and through the plastic bag. Two samples had been measured both ways; one gave a ratio of 12.7:1.0, the other 7.1:1.0. If one strikes a simple average, that is, a ratio of $10: 1$, then some $90 \%$ of the radiation was absorbed by the thicker plastic.
} 
The results of smear analysis showed that all smears were $\leq 250 \mathrm{dpm}$. Because the washer test assemblies are very small, they do not have enough surface area $\left(100 \mathrm{~cm}^{2}\right)$ for a standard green-tag test.

The 450-mL sample of used rinse solution did not have measurable radioactivity when counted in the NOMAD gamma-scanning system. In other words, no gamma-emitting radioactive species were detected in the filtered solvent. However, the effects of self-shielding by the liquid and of shielding by the glass bottle were not measured, and the amounts of beta emitters present, if any, could not be determined by this method.

\subsection{RUN 2, WTA-3}

WTA-6, chosen for the second run, had the highest activity of the WTAs exposed to the atmosphere and filters in Cell 3, Building 3047. The decrease in total activity, as measured by the pancake beta-gamma probe, with cleaning cycle is presented in Table 3 and Fig. 3. For comparison purposes, the unshielded probe results for WTA-3 are also presented in the figure. A much larger effect of the first cleaning cycle is evident for the hotter sample. The largest change occurred in the first cycle (down to about $14 \%$ of the starting value) and was followed by a plateau. A second decrease was noted when the Krytox wash solution was used, and a steady decrease in residual activity was noted with increasing cycles (terminating with about $8 \%$ left). The WTA was disassembled for the last two cycles. After disassembly and one further cleaning cycle and one rinse cycle, the final probe reading reached $820 \mathrm{cpm}$, approximately $4 \%$ of the starting value. The total cleaning time was about $30 \mathrm{~min}$.

The results of the gamma-scan analyses, which are presented in Table 4 and Fig. 4, indicate that the first four cleaning cycles reduced the ${ }^{60} \mathrm{Co}$ to about $4 \%$ of its original value. All other isotopes were "less than" numbers, and two upper limit values were all that could be calculated 
( $\leq 42 \%$ remaining for ${ }^{154} \mathrm{Eu}$ and $\leq 13 \%$ remaining for ${ }^{191}$ Os) for the first four cleaning cycles. The curves plotted in Fig. 4 are all upper limit curves, indicating that the decontamination may have been better than shown.

The results of smear analysis showed all smears were $s 340 \mathrm{dpm}$. Because the WTAs are very small, they do not have enough surface area $\left(100 \mathrm{~cm}^{2}\right)$ for a standard green-tag test.

\subsection{SUMMARY OF THE WTA RESULTS}

The two runs with the WTAs followed similar patterns. A significant amount of activity was removed in the first cleaning cycle with pure PF 5070, but three further treatments resulted in little additional decontamination. The use of wash solution resulted in a steady decrease in residual activity with three additional cycles of wash followed by a rinse cycle. Disassembly of WTA-3 and two further cycles of cleaning (one wash solution, one rinse) resulted in further removal of radioactive species. The smear-test results indicated good removal of loose particulates, but they cannot be related to standard green-tag tolerances because of the small size of the WTAs.

\subsection{RUN 3, MANIPULATOR WRIST HOUSING (WL)}

A used and previously decontaminated wrist housing from the slave end of a manipulator was used for the third run. This provided a good test of whether additional cleaning using the ESI process was possible. The run consisted of three cycles of cleaning with wash solution, followed first by a rinse cycle and then another wash cycle.

The results showed some additional cleaning took place, but it was selective (Table 5 and Fig. 5). The probe readings were relatively constant until the wrist assembly was taken apart and the parts cleaned by another wash cycle. This constancy could imply that the isotopes responsible 
for the bulk probe readings were not removed by this process; however, it is known that beta emitters are prone to self-shielding and that such readings are not proportional to the quantities present when they are present in "thick" layers. If the beta emitters were diffused into the outer surface of the housing, decontamination might not greatly reduce the probe readings. The probe readings decreased after disassembly. Because the geometry also changed on disassembly, the probe data are ambiguous.

The gamma scans, however, made after the second, fourth, fifth, and sixth cycles, showed significant decontamination was taking place. As seen in Table 6 and Fig. 6, decontamination from ${ }^{60} \mathrm{Co}$ and ${ }^{152,154} \mathrm{Eu}$ was continuous throughout the procedure. ${ }^{12}$ After three cycles of wash and one of rinse, about $50 \%$ of the ${ }^{60} \mathrm{Co}$ had been removed, and about $30 \%$ of the combined europium isotopes had been removed. ${ }^{13}$ After disassembly (with one cleaning cycle before and one after disassembly), the results for ${ }^{60} \mathrm{Co}$ appeared to be essentially unchanged, while the decontamination of the ${ }^{152.154} \mathrm{Eu}$ isotopes continued until about $55 \%$ was removed. The treatment did not remove the "crud" efficiently, which was a complicating factor.

The final, extended cleaning cycle with wash solution after disassembly did not appear to cause any significant changes in the quantities of ${ }^{60} \mathrm{Co}$ and ${ }^{152,154} \mathrm{Eu}$. The corrosion found when the parts were removed from the wrist housing assembly provided two explanations for the relatively low cleaning efficiencies noted. The first observation is that some of the contamination was trapped in such a way that the cleaning liquids could not get to it. The second observation is that the ESI process does not claim to remove fixed contamination from surfaces - it is useful

\footnotetext{
${ }^{12}$ According to the gamma scan information, the NOMAD system could not reliably distinguish between the two europium isotopes, and the values reported for them were summed for this analysis.

${ }^{13}$ All of the other isotopes were reported as "less than" values.
} 
mainly for adherent particulates. (A third explanation is, of course, that the previous cleaning cycles with wet chemicals had "fixed"some of the contamination to tiie surface.)

The change in appearance of the inner surface of the housing (it looked brighter and slightly rougher) and the presence of a few metallic shards in the used cleaning liquids after sonification were noted without further analysis or consideration.

The results of smear analyses, which are given in Table 7, showed that smears of the disassembled housing decreased to $\leq 710 \mathrm{dpm}$ after six cycles of cleaning and disassembly. Some of the separated parts and "crud" samples were more highly contaminated. The disassembled nut had high levels of smearable contamination $(37,440 \mathrm{dpm})$ on it after cycle 5 . It was not smeared after cycle 6 . The smear containing "crud" read $2380 \mathrm{dpm}$. The probe results were above greentag tolerance.

The analysis of a $100-\mathrm{mL}$ sample of wash solution filtered by gravity through a $0.2-\mu \mathrm{m}$ filter showed that the filtration removed the radioactive materials to levels well below those permitted for reuse or disposal. ${ }^{14}$

\footnotetext{
${ }^{14}$ These levels might be reduced even further by filtration through a finer filter $(0.1 \mu \mathrm{m})$, if desired.
} 


\section{CONCLUSIONS}

1. The tests of the ESI process with a variety of radioactive isotopes and forms of contamination show that ultrasonic agitation in these fluorocarbon liquids can remove the radioactive contamination.

2. The effectiveness of the removal is increased by using a surfactant in the fluorocarbon liquid.

3. Decontamination was still occurring when the tests were terminated, and additional time would have increased the effectiveness.

4. To be effective, the contamination must be "available" to wetting by the cleaning agents and not chemically bound to the surface.

5. These preliminary experiments indicate that filtration should be an effective method for removing radioactive materials from the process streams, allowing them to be recycled for further use. 


\section{RECOMMENDATIONS FOR FUTURE WORK}

1. Perform larger scale tests using a continuous process with circulating liquids and in-line filters on a wider variety of contaminated items (i.e., electronic and electrical).

2. Optimize the ESI process. 


\section{REFERENCES}

Ashley, K. C., 1984. "Precision Cleaning Using High Pressure Freon R," pp. 20-23 in Proc. 30th Annual Technical Meeting of the Institute of Environmental Sciences.

Ayers, J. A., 1970. "Decontamination of Nuclear Reactors and Equipment," p. 4 in Sect. 1, The Ronald Press Company, New York.

Bond, R. D., and A. Kearsey, November 1984. Ultrasonic and Immersion Cleaning: A Comparison Using Aqueous and Fluorocarbon Solvents, Report AEEW-R-1903, AEE, Winfrith, United Kingdom.

Gallagher, P. M., V. J. Krukonis, and R. Kaiser, January 1992. Freon (CFC-113) Solvent Replacement: A New Process for Precision Parts Cleaning, Phase 1 Final Report, U.S. Air Force, Ballistic Missile Organization, Norton AFB, California.

Kaiser, R., and O. K. Harling, 1993. Enhanced Remioval of Radioactive Particles by Fluorocarbon Surfactant Solutions, Draft final report, U.S. Nuclear Regulatory Commission, Report NUREG/CR/NRC-04-92-109.

Rankin, W. N., and J. F. McGlynn, 1990. Overview of Decontamination Technology, DOE Report WSRC-RP-89-1080 (also CONF-900132-2, 1990). 
D. -

$$
\text { 悬 }
$$


ORNL DWG 93A-458

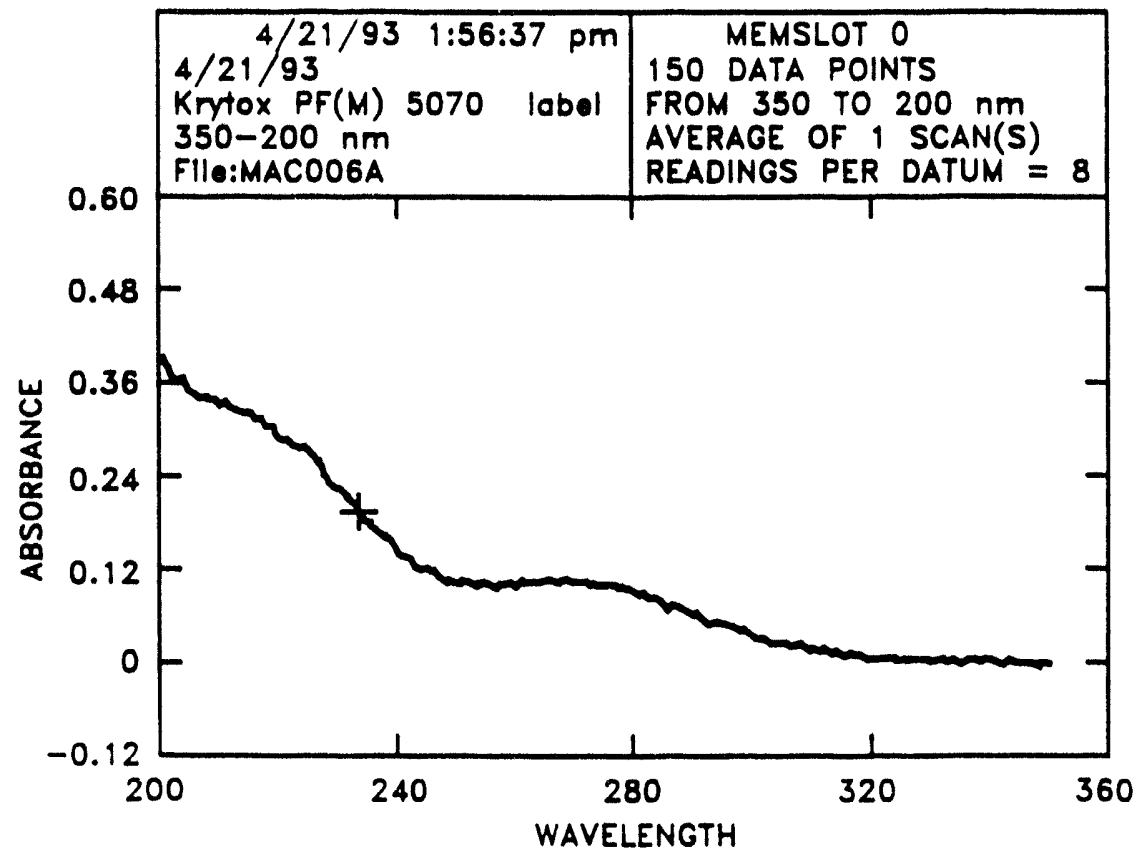

Fig. A.1. Absorbance of wash solution for $\mathrm{Krytox}(\mathrm{M})$ in PF-5070.

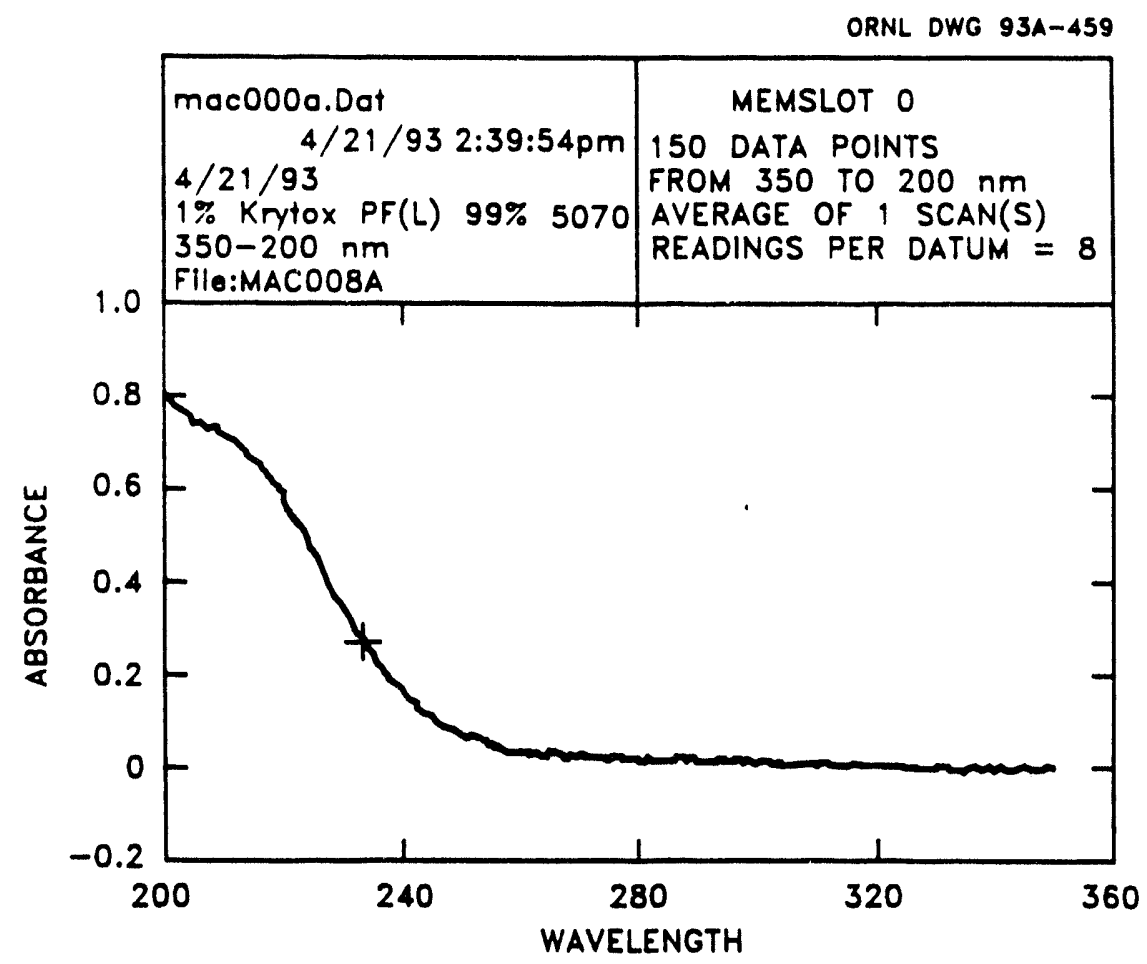

Fig. A.2. Absorbance of wash solution for Krytox(L) in PF-5070. 


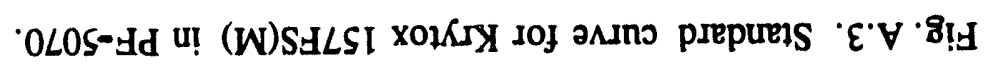

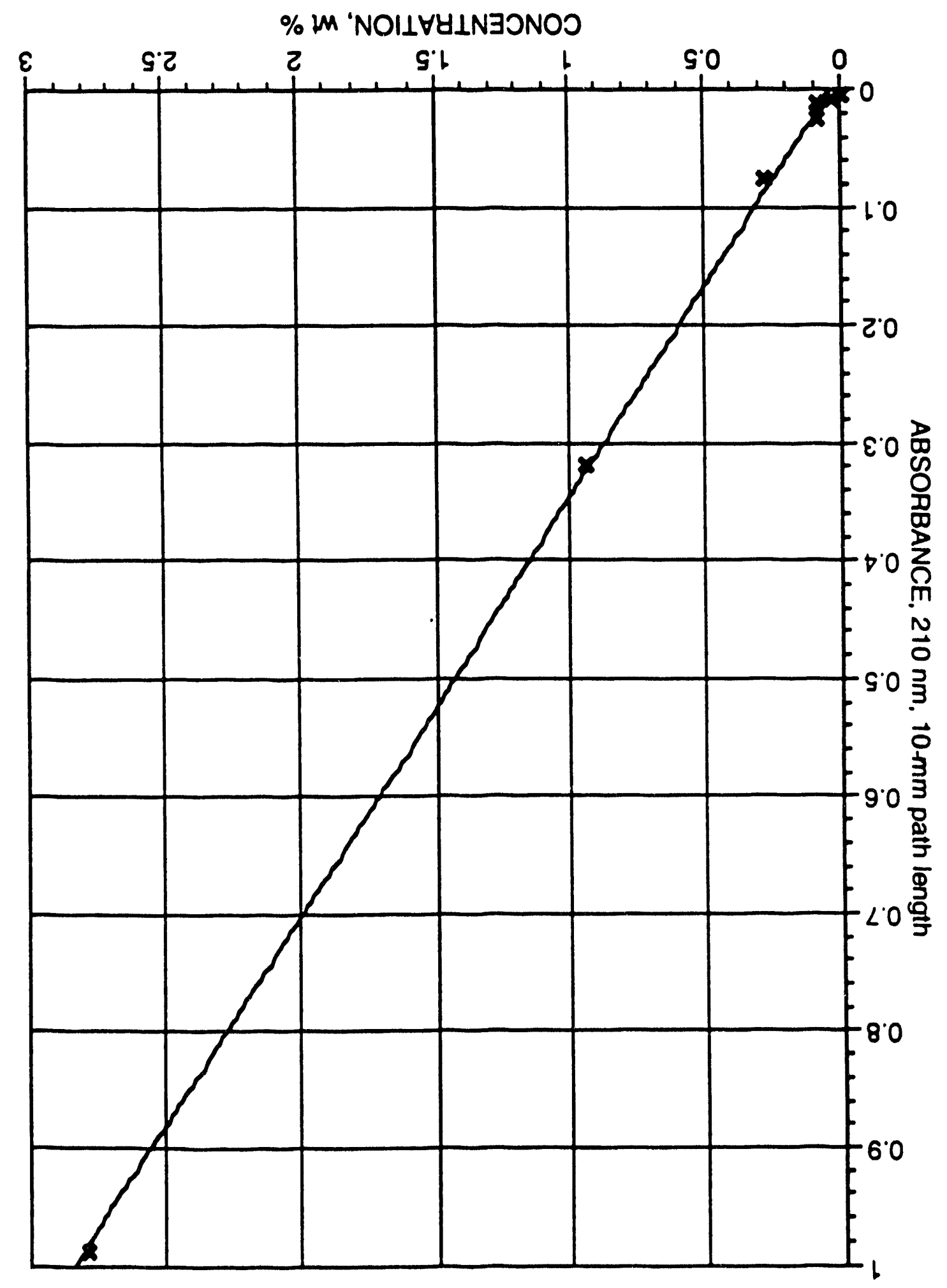


Table A.1. Background counts on the probe

\begin{tabular}{|c|c|c|c|c|c|c|c|c|}
\hline \multicolumn{3}{|c|}{ Run 1 , WTA-6 } & \multicolumn{3}{|c|}{ Run 2 , WTA-3 } & \multicolumn{3}{|c|}{ Run $3, \mathrm{WL}$} \\
\hline Date & $\mathrm{cpm}$ & Time & Date & cpm & Time & Date & $\mathrm{cpm}$ & Time \\
\hline \multirow[t]{6}{*}{$4 / 19 / 93$} & 196 & $12: 45$ & $4 / 20 / 93$ & 142 & $15: 15$ & $4 / 22 / 93$ & $178^{a}$ & $8: 15$ \\
\hline & 201 & $13: 22$ & & 135 & $15: 40$ & & $158^{a}$ & $8: 21$ \\
\hline & 225 & $13: 39$ & & 145 & $16: 00$ & & 181 & $8: 21$ \\
\hline & 213 & $13: 43$ & & 158 & $16: 15$ & & 136 & $8: 35$ \\
\hline & 207 & $13: 56$ & $4 / 21 / 93$ & $171^{a}$ & $7: 20$ & & 139 & $8: 55$ \\
\hline & 238 & Time? & & 143 & 8:05 & & 137 & $9: 13$ \\
\hline \multirow{3}{*}{$\begin{array}{l}\text { Average } \\
\text { std. dev. }\end{array}$} & 213.3 & & & 154 & 8:07 & & 138 & $9: 16$ \\
\hline & 15.7 & & & 142 & $8: 30$ & & 169 & $9: 52$ \\
\hline & & & & 144 & $8: 40$ & & 139 & $9: 53$ \\
\hline \multirow[t]{10}{*}{$4 / 20 / 93$} & 150 & Time? & & 140 & $10: 12$ & & 153 & $10: 05$ \\
\hline & 148 & 9:30 & & 133 & $10: 15$ & & 149 & $10: 14$ \\
\hline & 154 & $10: 06$ & $\begin{array}{l}\text { Average } \\
\text { std. dev. }\end{array}$ & 146.1 & & & 152 & $12: 30$ \\
\hline & 121 & $10: 28$ & & 11.0 & & & 165 & $14: 11$ \\
\hline & 142 & $10: 39$ & & & & & 141 & $14: 13$ \\
\hline & 167 & $13: 30$ & & & & & 120 & $14: 45$ \\
\hline & 147 & $14: 15$ & & & & & 129 & $14: 47$ \\
\hline & 150 & Time? & & & & & 130 & $15: 45$ \\
\hline & 136 & Time? & & & & Avg. & 147.88 & $\begin{array}{l}\text { Std. } \\
\text { dev. }\end{array}$ \\
\hline & 310 & Omitted & & & & & & \\
\hline \multirow{2}{*}{$\begin{array}{l}\text { Average } \\
\text { std. dev. }\end{array}$} & 146.1 & & & & & & & \\
\hline & 12.7 & & & & & & & \\
\hline
\end{tabular}

Instrument has not stabilized (still cold). 
51

Table A.2. Probe dan and averages: ESI Runs 1 through 3

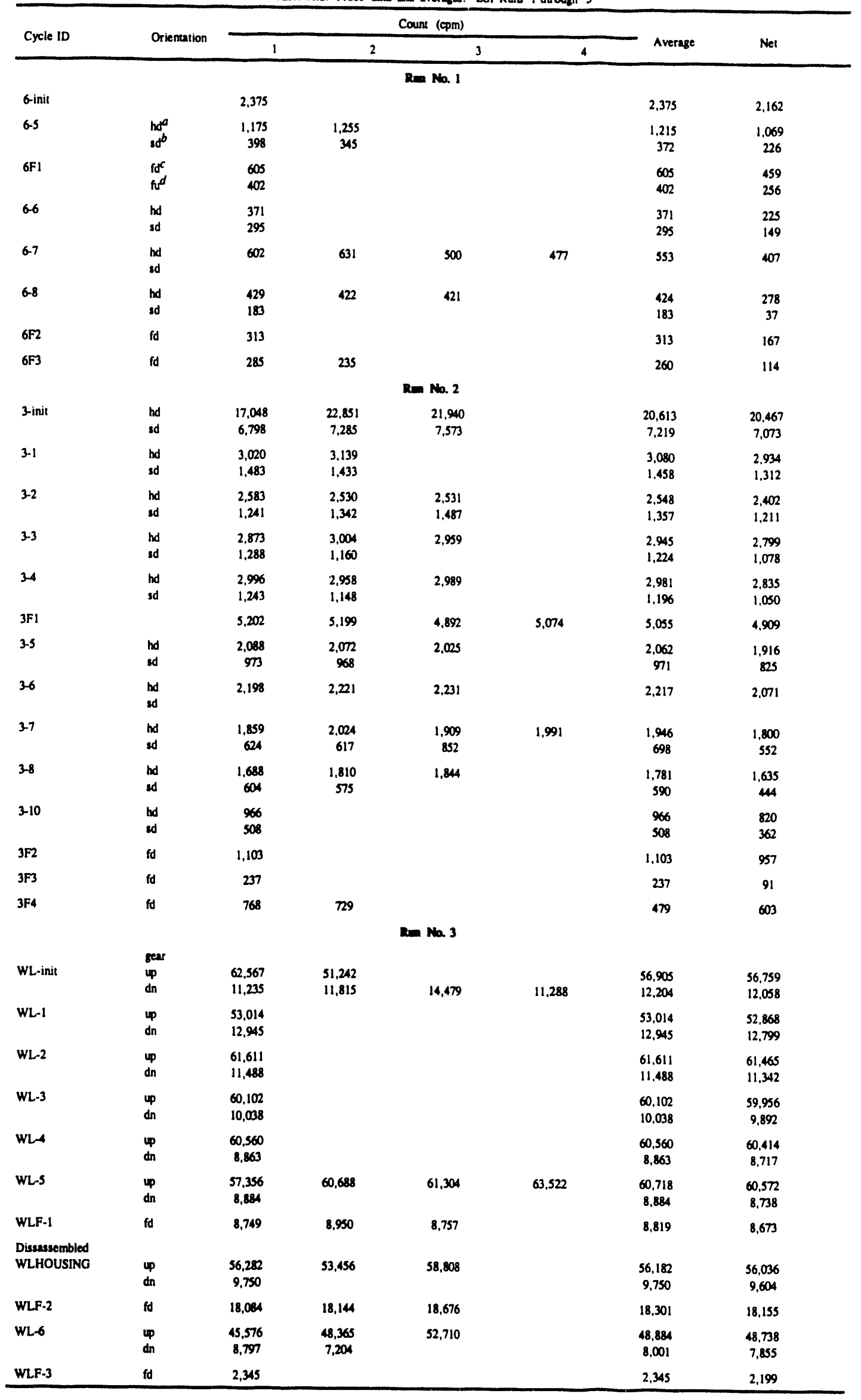

and = head down.

$b_{\text {sd }}=$ screw down.

$c_{\mathrm{fd}}=$ frce down.

$d_{f u}=$ face up. 
Table A.3. Comparison of probe readings for sample WTA-6 through a plastic bag and through a petrie dish

\begin{tabular}{|c|c|c|c|c|c|}
\hline \multirow[b]{2}{*}{$\begin{array}{l}\text { Specimen } \\
\text { ID }\end{array}$} & \multicolumn{2}{|c|}{ Net probe reading (cpm) } & \multirow[b]{2}{*}{ Orientation } & \multirow[b]{2}{*}{ Ratio } & \multirow[b]{2}{*}{$\begin{array}{c}\text { Ratio } \\
\text { approximation }\end{array}$} \\
\hline & $\begin{array}{c}\text { Through } \\
\text { bag }\end{array}$ & $\begin{array}{c}\text { Through } \\
\text { petrie } \\
\text { dish }\end{array}$ & & & \\
\hline $6-1$ & & 104 & Not known & & \\
\hline $6-2$ & & 28 & Screw down & & \\
\hline $6-3$ & & 11 & Screw down & & \\
\hline $6-4$ & & 85 & Head down & & \\
\hline $6-4$ & & 42 & Screw down & & \\
\hline $6-5$ & 1069 & 84 & Head down & $12.7: 1.0$ & $10: 1$ \\
\hline $6-5$ & 226 & 32 & Screw down & 7.1:1.0 & $10: 1$ \\
\hline $3 F 1-1$ & 4928 & 1312 & Face down & $3.8: 1.0$ & $4: 1$ \\
\hline $3-7$ & 1733 & 478 & Head down & $3.6: 1.0$ & $4: 1$ \\
\hline
\end{tabular}




\section{INTERNAL DISTRIBUTION}

1. J. M. Begovich

2. J. T. Bell

3-7. C. E. Benson

8. R. N. Borum

9. C. H. Byers

10. E. D. Collins

11. T. B. Conley

12. A. G. Croff

13. T. L. Donaldson

14-15. D. Foster, Jr.

16. W. Fulkerson

17. R. K. Genung

18. I. G. Gross

19. K. W. Haff

20. D. W. Holladay

21. A. M. Krichinsky
22. E. K. Johnson

23. T. E. Kent

24. C. P. McGinnis

25-29. E. S. Meyers

30-34. B. D. Patton

35. J. E. Parfitt

36. H. X. Phillips

37. D. W. Ramey

38. S. M. Robinson

39. T. W. Schmidt

40. L. M. Toth

41. Central Research Library

42. Y-12 Technical Library, Document Reference Section

43. ORNL Patent Section

44-46. Laboratory Records - RC

\section{EXTTRNAL DISTRIBUTION}

47. R. Kaiser, Entropic Systems, Inc., P.O. Box 397, Winchester MA 01890-0597

48. V. C. A. Vaughen, Engineering and Safety Consulting Services, 1136 Harrogate Drive, Knoxville TN 37923-1953

49. Office of Assistant Manager, Energy Research and Development, DOE-ORO, P.O. Box 2001, Oak Ridge TN 37831

50-51. Office of Scientific and Technical Information, P.O. Box 62, Oak Ridge TN 37831 


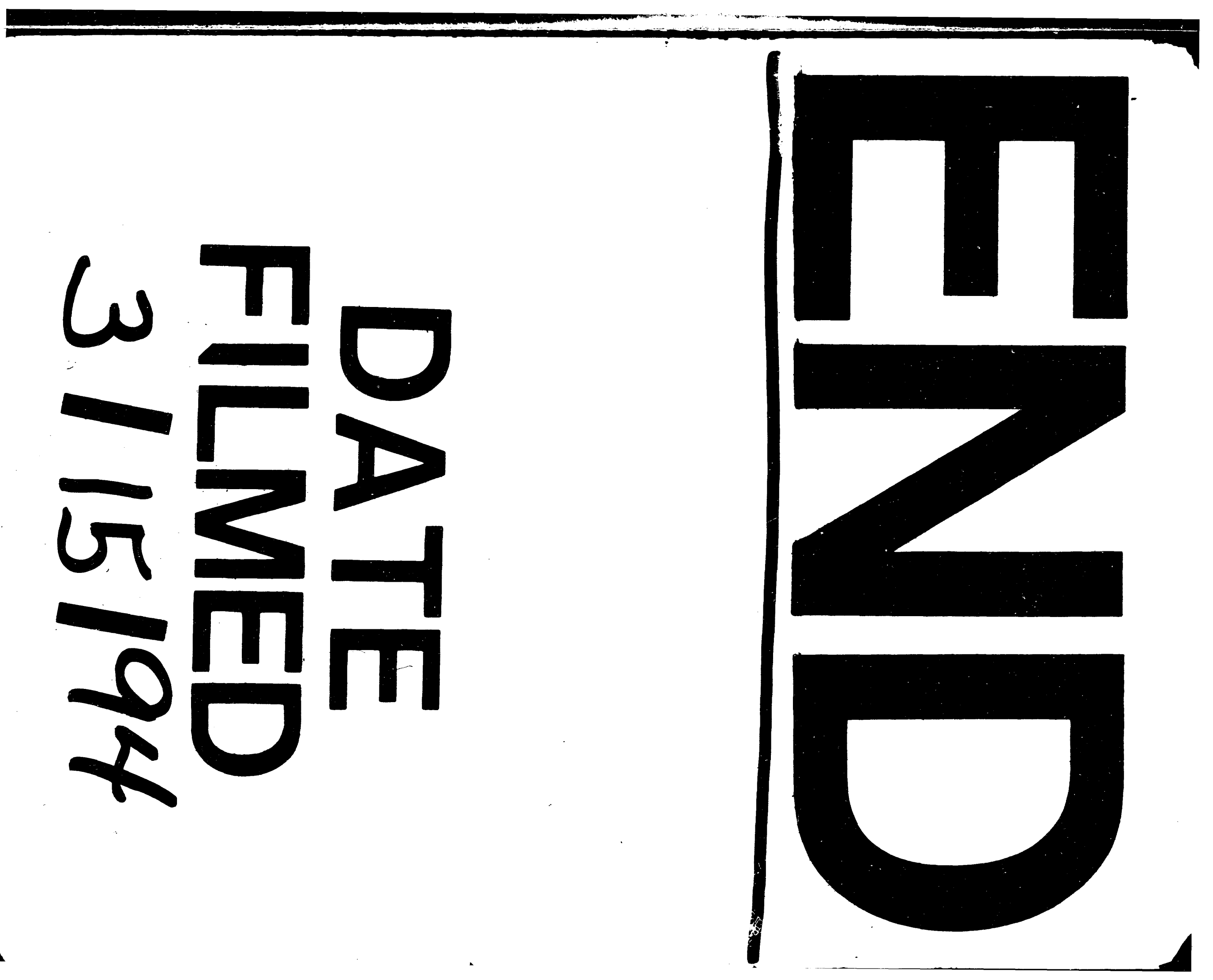


